\title{
Novel drug delivery systems targeting oxidative stress in chronic obstructive pulmonary disease: a review
}

You $\mathrm{Xu}^{1,2}$, Hongmei Liu ${ }^{1}$ and Lei Song ${ }^{1^{*}}$

\begin{abstract}
Oxidative stress is significantly involved in the pathogenesis and progression of chronic obstructive pulmonary disease (COPD). Combining antioxidant drugs or nutrients results in a noteworthy therapeutic value in animal models of COPD. However, the benefits have not been reproduced in clinical applications, this may be attributed to the limited absorption, concentration, and half-life of exogenous antioxidants. Therefore, novel drug delivery systems to combat oxidative stress in COPD are needed. This review presents a brief insight into the current knowledge on the role of oxidative stress and highlights the recent trends in novel drug delivery carriers that could aid in combating oxidative stress in COPD. The introduction of nanotechnology has enabled researchers to overcome several problems and improve the pharmacokinetics and bioavailability of drugs. Large porous microparticles, and porous nanoparticleencapsulated microparticles are the most promising carriers for achieving effective pulmonary deposition of inhaled medication and obtaining controlled drug release. However, translating drug delivery systems for administration in pulmonary clinical settings is still in its initial phases.
\end{abstract}

Keywords: Oxidative stress, Chronic obstructive pulmonary disease, Drug delivery, Nanoparticles, Microparticles, Nanocomposite microparticles

\section{Introduction}

The respiratory tract is constantly exposed to multiple endogenous and exogenous oxidants and develops a series of defence mechanisms to limit the oxidative damage. Oxidative stress, caused by an imbalance between increased oxidative burden and the defective antioxidant system, is involved in cellular and tissue damage related to the pathogenesis and progression of many acute and chronic respiratory diseases including chronic obstructive pulmonary disease (COPD) $[1,2]$. COPD is characterised by chronic bronchitis and emphysema, which present with that feature persistent airway inflammation,

\footnotetext{
*Correspondence: Isong@jlu.edu.cn

${ }^{1}$ Department of Respiratory Medicine, Key Laboratory of Organ

Regeneration \& Transplantation of the Ministry of Education, The First Hospital of Jilin University, Changchun 130061, People's Republic of China

Full list of author information is available at the end of the article
}

ultimately leading to a gradual progression of irreversible airway obstruction. It has become a global health problem ranked as the fourth leading cause of death worldwide. There were up to 2.8 million deaths from COPD in 2010 globally and about 175 million patients were suffering from this disease in 2015 [3]. Although therapeutic strategies have advanced to help ease symptoms and prevent complications, there is no cure for COPD. Therefore, new approaches are urgently needed to slow or even stop the progression of this disease and reduce the mortality.

The presence of excessive reactive oxygen species (ROS) in the airway plays a key driving role in the pathogenesis and progression of COPD $[4,5]$. Cigarette smoke and biomass fuel-induced oxidative and aldehyde/carbonyl stress are closely associated with the progression and exacerbation of COPD. The oxidant generates airway inflammation that leads to the production of proinflammatory cytokines [6, 7]. It also recruits inflammatory 
cells such as neutrophils, eosinophils, lymphocytes, and macrophages by potentiating the action of histamine, which injures lung tissues and causes inflammation [8, 9]. Targeting systemic and local oxidative stress using antioxidants/redox modulating agents, or boosting the endogenous levels of antioxidants are strategies for the treatment and management of COPD.

Traditional pharmacotherapy for drug delivery to the lungs can be classified according to the type of therapeutic agents $[10,11]$. Unfortunately, COPD cannot be completely cured using pharmacotherapy alone owing to biological barriers, low drug bioavailability and associated safety concerns [12, 13]. Advanced strategies for novel drug delivery systems (DDS) have recently demonstrated promising results as a targeted drug delivery pharmacotherapy. Based on their innate physical properties, novel DDS can improve the pharmacokinetics of the loaded therapeutics and target cells to minimise the adverse effects of drugs $[11,14]$.

Reviews related to the importance and use of nanoparticles for respiratory diseases are available [15]; However, a comprehensive summary of novel drug delivery systems has not been presented as yet. Domej et al. reviewed the general relevance of free radicals in the development and progression of both COPD and pulmonary emphysema as well as novel perspectives on therapeutic options. The review is very useful when selecting drugs to treat of COPD, but not while selecting delivery systems [16]. Other reviews exploring novel delivery systems related to oxidative stress are not mainly focused on chronic respiratory diseases but not COPD [17]. Owing to the particular pathogenesis and progression of chronic respiratory diseases, the delivery systems for COPD will, by necessity, need to be different from those developed for other lung diseases. A comprehensive review that introduces the role of delivery systems in the treatment of oxidative stress is very important. Therefore, in this review, we discussed the role of oxidative stress and the use of novel delivery systems in the treatment of oxidative and airway inflammation.

\section{Redox systems in the lung}

Under physiological conditions, ROS and reactive nitrogen species (RNS) can be naturally generated intracellularly by mitochondrial respiration, xanthine/xanthine oxidase, or NADPH oxidase system [18]. Xanthine/ xanthine oxidase and the NADPH oxidase system are mainly located in phagocytes and epithelial cells [19]. In response to pathological stimuli, such as viral or bacterial infections, chemical and mechanical factors, phagocytes and endothelial cells in the airways rapidly release large amounts of superoxide anion $\left(\mathrm{O}^{-}{ }_{2}\right)$ and hydrogen peroxide $\left(\mathrm{H}_{2} \mathrm{O}_{2}\right)$, which is referred to as an oxidative burst. The highly specialized function of lungs facilitates oxygen exchange and is, thus, constantly exposed to exogenous ROS, such as cigarette smoke, industrial air pollutants, and airborne pollutants. Tobacco smoke is a mixture of over 4700 chemical compounds including oxidants, which are present at high concentration [20]. Industrial and other airborne pollutants are also sources of oxidants that could be responsible for increased prevalence of COPD in non-smokers [21]. In previous studies, we found that particulate matter (PM) with an aerodynamic diameter $\leq 2.5 \mu \mathrm{m}$ (PM2.5) significantly induced ROS generation through epigenetic regulation, leading to airway epithelial cell injury and aberrant inflammatory response [22, 23]. The sources of ROS and their influence can be seem in Fig. 1 .

ROS modulate the function of all classes of biomolecular, targeting almost all substrates in the cell. Lipids are the most susceptible to oxidation, which results in lipid peroxidation [24]. Lipid peroxidation products such as malondialdehyde, 4-hydroxynonenal and isoprostanes, impair membrane function, inactivate membrane-bound receptors, and increase tissue permeability. ROS can act on proteins to cause side-chain oxidation, backbone fragmentation, unfolding, and misfolding, all resulting in loss of activity [25]. ROS can also damage nucleic acids and cause DNA-protein crosslinking, strand breaking, and alteration in purine and pyridine bass structures, resulting in DNA mutations [26]. The marker of DNA damage is represented by 8-hydroxydeoxyguanosine. These harmful actions lead to different forms of lung injury such as tissue damage, cell activation, and proliferation. Additionally, the damage of the mitochondrial membranes and protein structure can enhance the generation of ROS and lead to DNA impairment and cell death by apoptosis [27].

In healthy lungs, antioxidants, such as catalase (CAT), superoxide dismutase (SOD) and glutathione peroxidase $(\mathrm{GPx})$ provide an endogenous biological defence against cellular or organ injury caused by ROS. These antioxidant genes are predominantly regulated by nuclear factor-erythroid 2-related factor 2 (Nrf2) signalling, which plays a key role in sensing and defying oxidative stress [28]. As a transcription factor, Nrf2 is generally located in the cytoplasm by forming a heterodimer with its repressor Kelch-like ECH-associated protein 1 under physiological condition. In response to oxidative stress, $\mathrm{Nrf2}$ is liberated from the inactive state and then translocated into the nucleus, promoting the expression of antioxidant enzymes by binding to the antioxidant response element [28]. The normal function of Nrf2 signalling is crucial for the maintenance of physiological processes in the lungs. Experiments in Nrf2 knockout mice show enhanced ROS 


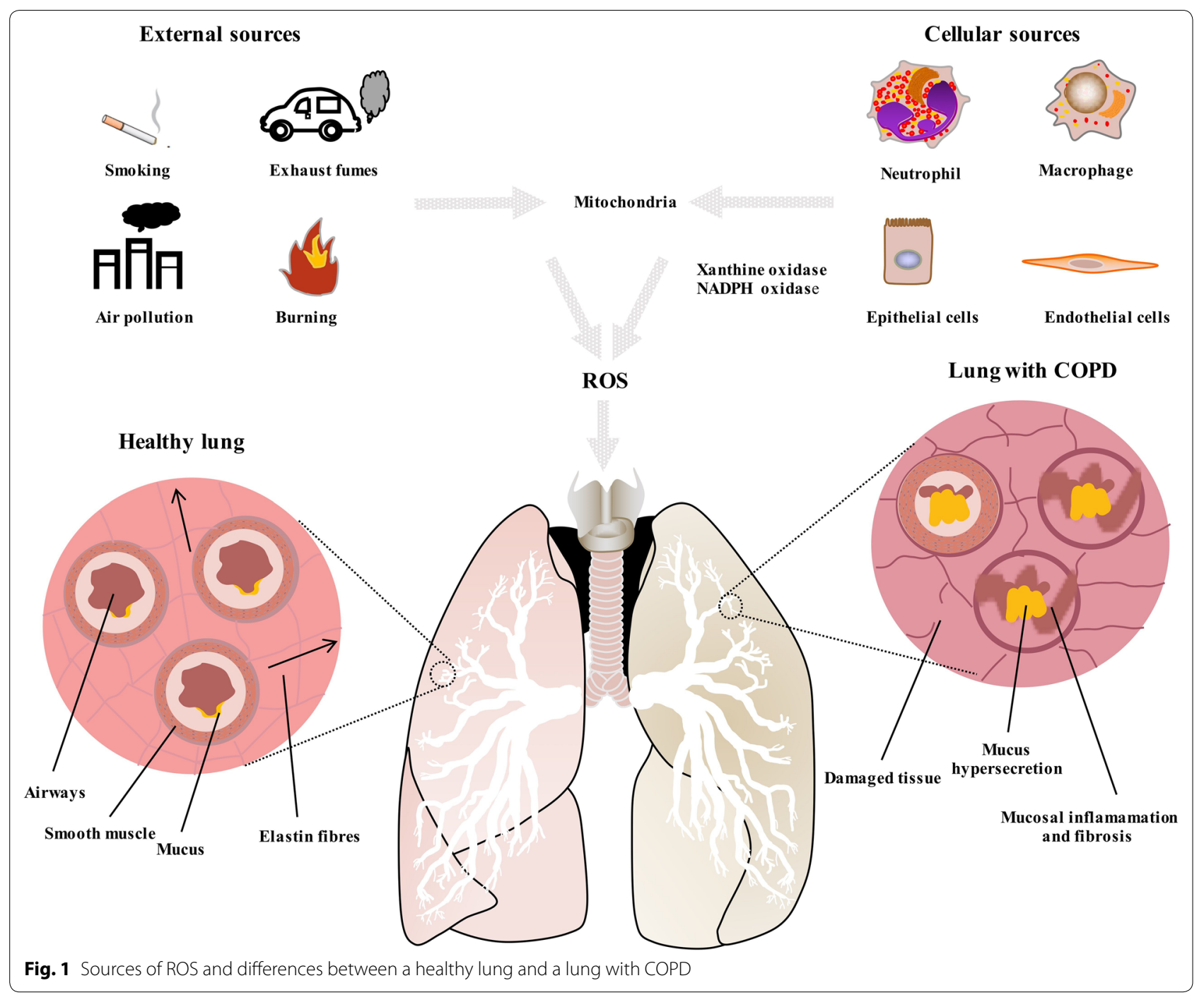

accumulation, inflammatory response, cellular injury in the airway, and increased sensitivity to physical or chemical stimuli [29-32]. Defective Nrf2 signalling was determined in COPD patients and correlated with a decline in lung function and cigarette pack-year [33, 34]. Data from clinical and basic research have identified the protective effects of Nrf2 on COPD. For instance, Nrf2 restored corticosteroid sensitivity of peripheral blood mononuclear cells from COPD patients and, human monocytic U937 cells exposed to cigarette smoke extract [35]. Recent findings on the mechanisms of Nrf2-mediated lung protection in COPD have been reviewed by Barnes [36]. Although it is difficult to develop specific and effective Nrf2 agonist, drugs and strategies targeting Nrf2 signalling are being considered in the treatment of COPD.

\section{Mechanisms and damaging effects of oxidative stress in COPD}

Oxidative stress is now recognised as a major predisposing factor in the pathogenesis of COPD and an excellent target for COPD therapies [37]. Oxidative stress involved in the pathogenesis of COPD is not only the result of the increased burden of oxidants but also owing to a decrease in antioxidative potential [38]. There is clear evidence of increased oxidative burden in patients with COPD. Increased levels of free-radical biomarkers have been detected in the epithelial lining fluid, breath and urine of cigarette smokers and patients with COPD [39-41]. The levels of $\mathrm{H}_{2} \mathrm{O}_{2}$ and arachidonic acid is found to be markedly increased in the exhaled breath condensate of COPD relative to those of the healthy controls [42-44]. Oxidative stress 
Table 1 Main mechanisms of oxidative-burden related COPD

\begin{tabular}{|c|c|c|}
\hline Mechanism & Outcome & Refs. \\
\hline Imbalance of biological molecules & $\begin{array}{l}\text { Reduced antioxidant and antiprotease enzyme activity (SOD, CAT, GPx, a1 antit- } \\
\text { rypsin); } \\
\text { Altered expression of ROS-related enzymes (decreased in CAT, GPx, SOD, and } \\
\text { increase in iNOS); } \\
\text { Activation of metallo proteinases }\end{array}$ & {$[45-49]$} \\
\hline Intracellular signaling & $\begin{array}{l}\text { Altered expression of ROS related enzymes (decreased in CAT, GPx, SOD, and } \\
\text { increase in iNOS) }\end{array}$ & {$[50,51]$} \\
\hline Mitochondrial respiration & Altered mitochondrial function & {$[46,48,52,53]$} \\
\hline $\begin{array}{l}\text { Upregulation of gene transcription (NF-KB and, } \\
\text { AP-1) and increase in cellular cytokine produc- } \\
\text { tion }\end{array}$ & $\begin{array}{l}\text { Increased gene expression of inflammatory mediators and cytokines (IL-1, TNF-a, } \\
\text { IL-8, GM-CSF, iNOS) }\end{array}$ & {$[54]$} \\
\hline Nuclear histone acetylation/deacetylation balance & $\begin{array}{l}\text { Decreased HDAC2 activity and protein expression chronic inflammation (chronic } \\
\text { remodelling) }\end{array}$ & {$[55,56]$} \\
\hline Remodelling of DNA/chromatin & Decreased histone deacetylase 2 & {$[57]$} \\
\hline
\end{tabular}

iNOS, inducible nitric oxide synthase isoenzymes; SLPI, secretory leukocyte protease inhibitor; a1 AT, alpha-1-antitrypsin; IL-1, interleukin 1; NF-KB, nuclear factor kappa B; IL-8, interleukin-8; GM-CSF, TNF-a, tumor necrosis factor-a; granulocyte macrophage colony-stimulating factor; iNOS, inducible nitric oxide synthase; HDAC: histone deacetylase

involves several mechanisms that result in the obstructive symptoms observed in COPD (Table 1).

The pathogenesis of COPD involves several pathogenetic processes including oxidative stress, inflammation, protease/antiprotease imbalance, apoptosis, and cellular senescence [43, 58] (Fig. 2); however, the relative contribution of each of these pathologies to COPD varies among patients.

The major pathological features of COPD are obstructive bronchiolitis, emphysema, and mucus hypersecretion [59]. Oxidative stress might result the activation of the proinflammatory transcription factor, NF- $\mathrm{B}$, impaired antiprotease defences, cellular senescence, and corticosteroid resistance. Oxidative stress can impair the function of antiproteases, such as $\alpha 1$-antitrypsin and secretory leukoprotease inhibitor, thereby accelerating the breakdown of elastin in the lung parenchyma. Oxidative stress accelerates lung ageing because of the defective function of endogenous antiageing molecules such as sirtuins, which have a role in genomic stability and can protect against ageing [60]. The reduced activity and expression of sirtuin-1 eventually leads to cellular senescence. Senescent cells also release generate inflammatory proteins including TNF- $\alpha$, IL-1, IL-6, CXCL8, CCL2, and MMPs [61]. Corticosteroid resistance is caused by an imbalance in the expression of the proinflammatory enzymes in COPD patients. The damage caused by oxidative stress increases proinflammatory enzyme expression in COPD patients via a decrease in HDAC activity [62, $63]$ and an increase in histone acetyltransferase activity [6]. Therefore, patients with COPD respond poorly to corticosteroid treatment, which fails to suppress inflammation even in high doses of inhaled or oral corticosteroids are used [64]. Additionally, oxidative stress can reduce anti-inflammatory defence, such as CAT activity, which has been demonstrated to be significantly reduced in patients with COPD $[48,49]$. The levels of serum nitro-tyrosine [39] and lipid-peroxidation products increase in patients with COPD, resulting in increased systemic inflammation via the production of proinflammatory cytokines, ultimately causing cachexia [65] and thromboembolic events [66].

Oxidative stress also causes small-airway fibrosis. Epithelial cells are activated by cigarette smokingrelated vascular irritation and activation and result in the production of inflammatory mediators [67]. Epithelial cells in the small airways express TGF- $\beta$, which induces local fibrosis and narrowing of small airways. Oxidative stress causes airflow obstruction that leads to tissue hypoxia and could stimulate an inflammatory response [68]. It can also damage and cause apoptosis of airway epithelial cells [69-71]. These airway-epithelium injuries decrease the protective capacity of the epithelium against inhaled oxidants and further enhance inflammation. Therefore, oxidative stress causes airway inflammation, which gives rise to a further oxidative burden, thereby forming a vicious cycle.

ROS are known to increase mucus hypersecretion through neutrophilic activity [72] and contribute to the pathogenesis of chronic bronchitis. Increased neutrophil numbers in the airways can be detected in patients with acute COPD exacerbations. Epithelial growth factor receptors (EGFRs) play an important role in mucus hyperplasia and secretion. EGFRs can be activated by neutrophilic inflammation through neutrophil elastase 


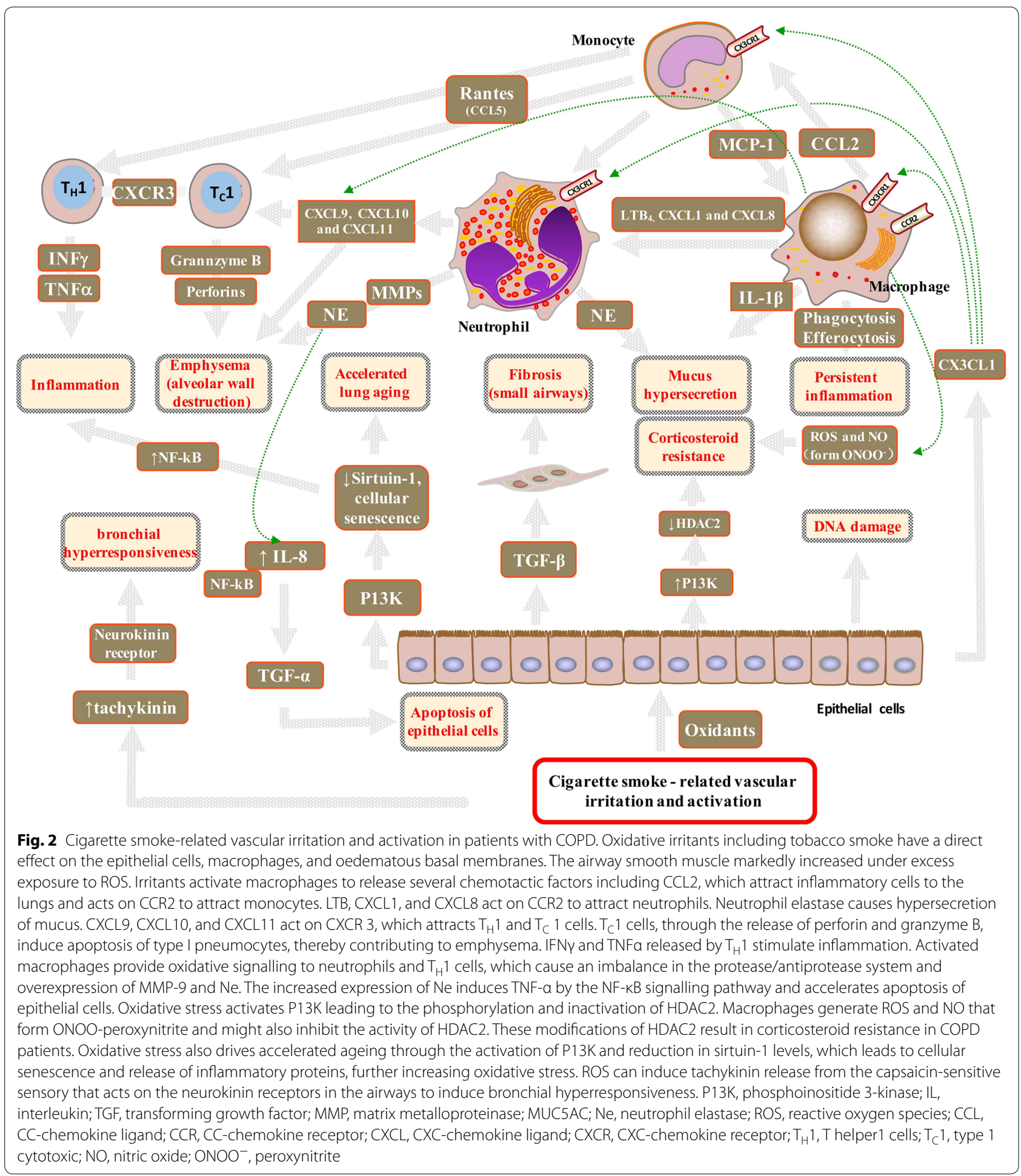

secretion and might contribute to mucus hypersecretion [73].

Further, oxidative stress can increase the risk of bronchial hyperresponsiveness (BHR). Previous reports state that half of population of patients with COPD are diagnosed with BHR $[74,75]$. ROS can induce tachykinin release from the capsaicin-sensitive sensory that act on the neurokinin receptors in the airways to induce BHR [76]. Also, lipid-peroxidation products are reactive molecules that can cause smooth-muscle 
contraction and subsequently contribute to BHR [77]. BHR is a strong predictor of the progression of airway obstruction in early COPD patients who continue smoking.

Damage caused to DNA by oxidative stress can be repaired by efficient DNA-repair machinery. However, failure to repair double-stranded DNA breaks leads to an increased risk of developing lung cancer in COPD patients [78]. ROS also result in protein carbonylation that may lead to the generation of circulating autoantibodies that cause damage to alveolar cells, particularly in severe COPD [79].

\section{Therapy strategies}

Recent therapeutic choices for COPD include anticholinergics, $\beta 2$-agonists, and inhaled corticosteroids, all of which ameliorate symptoms rather than curing the disease $[80,81]$. There are no clinically available treatments that prevent COPD progression. Currently, several endogenous non-enzymatic and enzymatic antioxidants antioxidants are widely used to combat oxidative stress in the lungs. The commonly used nonenzymatic antioxidants include glutathione [82], ascorbic acid [83], uric acid [84], $\alpha$-tocopherol [85], and proteins used to prevent the Fenton and Haber-Weiss reactions [86]. The enzymatic antioxidants mainly include catalase, SOD isomers, and GSH-associated enzymes [87-89]. Although oxidative stress is an excellent target, these agents are not very effective. The most common obstruction faced by conventional antioxidant drugs involves airway immune response, mucous hypersecretion, inflammation, and low bioavailability. Overall, studies of anti-oxidants in COPD have been disappointing. There remains a considerable need to develop novel drug therapies for patients with COPD. However, the introduction of a novel DDS can help improve the pharmacokinetic behaviour of drug molecules inside a biological entity, such as the rapid absorption of the nano/mirco-drug owing to its high surface area. DDS can enable sustained release in the lung tissue, prolong drug circulation time, reduce dosing frequency, and improve patient compliance. Local DDS, such as inhaled medicines, might be an alternative that could decrease the incidence of side effects associated with high drug-serum concentrations.

\section{Novel drug delivery systems}

Novel DDS have gained increasing attention in the treatment of COPD owing to their advantages of targeted deposition, sustained release, biodegradation, reduced dosing frequency and well controlled size and surface charge. Owing to their small size, high surface-volume ratio, high stability, and unique physicochemical properties, nano/microcarriers can be utilized to incorporate hydrophilic and hydrophobic drugs as well as other biologics. These unique characteristics make nano/ mircocarriers a promising platform for improving the solubility, dissolution, and bioavailability of therapeutics. Novel DDS include liposomes, polymeric nanoparticles, solid lipid nanoparticles, polymeric micelles, dendrimers, nanoemulsion, nanosuspension, and microspheres, and microparticles (Fig. 3). However, the application of DDS in COPD is still in its early stages. The progress in designing novel DDS against oxidative stress, oxidative-stress triggered inflammation, and challenges in translating technology into the market are discussed in the following sections.

\section{Liposomes}

Liposomes are among the most established drug delivery platforms owing to their flexibility, biocompatibility, biodegradability, and nonimmunogenicity. Liposomes constructed using amphiphilic phospholipids have a spherical lipid structure containing an aqueous core [90]. The hydrophilic (aqueous core) and hydrophobic shell (spherical lipid structure) enable the transport of hydrophilic, hydrophobic, and amphiphilic molecules and make liposomes convenient for use in combination therapy, which is crucial for COPD treatment [91]. Many lipids commonly used to prepare liposomes have good compatibility with the lung tissue and can facilitate the intracellular delivery of several therapeutic agents via fusion with the plasma membrane lipids, receptor-mediated endocytosis, and phagocytosis owing to the diversity of the amphiphilic lipid molecules [92]. Liposomes are used in transporting hydrophilic, hydrophobic, and amphiphilic antioxidants as well as antioxidant enzymes to different organs and tissues for the treatment of oxidative stress-induced damage (Table 2).

Liposomes containing antioxidants are being studied for acute oxidant-related COPD. To date, liposomes have been widely used in the delivery of molecules with antioxidant properties, including the lipophilic antioxidants $\alpha$-tocopherol; hydrophilic antioxidant glutathione, NAC, and the antioxidant enzymes SOD and CAT. However, the effectiveness of SOD and CAT is limited owing to their unfavourable physicochemical properties. Liposomal-entrapment markedly increases the activity of these enzymes [103]. Other antioxidant-loaded liposomes show promising results. For example, Hoesel et al. tested NAC-loaded liposomes and showed that they reduced lung permeability index in acute (4-h) CEES-induced injury by a $59 \%$; Proinflammatory mediators in the bronchoalveolar lavage fluids from oxidant-expose lungs (CEES caused a 20-fold, fourfold, and 1.6-fold increase in CINC-1, IL-1 $\beta$, and TNF- $\alpha$, respectively) were reduced to baseline levels [99]. Curcumin-loaded liposomes are 


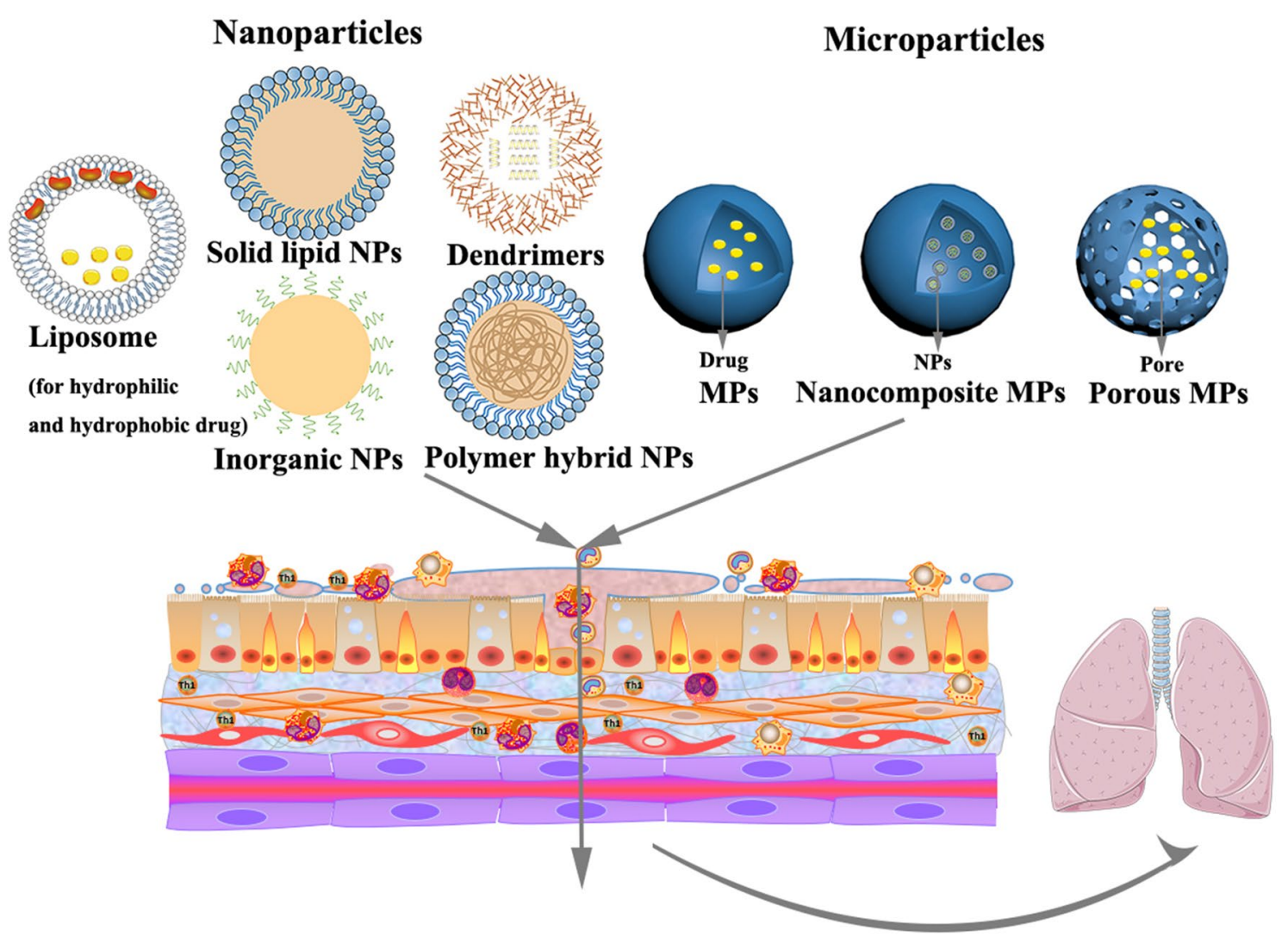

Fig. 3 Representative nanoparticles and microparticles used for delivering antioxidants in COPD

potential and safe delivery systems to prevent chronic inflammatory conditions and can be modified by coating their surface with chitosan or hyaluronan to protect both the phyto drug and vesicles and improve the local efficacy of curcumin. These liposomes improved the nebulisation performance and provided relatively good protection against oxidant-induced damage to the lungs. Particularly, a synergic effect of curcumin and hyaluronan was observed which resulted in a proliferative effect and a subsequent enhancement of the metabolic activity of cells [102]. To protect liposomes from degradation in vivo and prolong their activity, PEG was added to the surface of the liposomes, which generated liposomes with a hydrophilic 'sterically stabilised' surface. PEGylated liposomes have a lower affinity for macrophages in the mononuclear phagocyte system.

A major difficulty in translating liposome treatment from research to the clinic is delivery. Inhaled pharmacologic therapy is a cornerstone treatment for patients with COPD [104]. The administration of liposome could improve lung maintenance and lessen side effect. Thus, dry inhaled powder, Arikace and Pulmaquin, are currently in clinical-development phases [105]. Arikace is a dipalmitoyl-phosphatidylcholine and cholesterol liposome loaded with amikacin to treat Pseudomonas aeruginosa infections that affect the lung and ultimately lead to cystic fibrosis. Pulmaquin is a ciprofloxacin liposome used to the treat lung infections [106].

However, to date, inhaled liposome therapy has several limitations. Liposomes are associated with drug leakage owing to their relative instability during storage and nebulization and are also unstable during dehydration. For the product to be effective, it is essential to maintain the physical properties of liposomes after inhalation. Therefore, new approaches for preparing liposomes of increased stability are needed.

\section{Nanoparticles}

Nanoparticles offer a new approach for the targeted delivery of drugs to the lungs [107]. They have been used mainly to target the intracellular cell adhesion molecule and platelet endothelial cell adhesion molecule receptors present on the endothelial cells of the pulmonary airway. Nanoparticles can be used as carriers to transport drugs, such as NADPH oxidase inhibitors, SOD and CAT, to prevent oxidative stress in the respiratory system [108]. 
Table 2 Relevant studies focusing on liposomes for oxidative stress

\begin{tabular}{|c|c|c|c|c|c|c|}
\hline $\begin{array}{l}\text { Nanocarrier } \\
\text { composition }\end{array}$ & Drug & $\begin{array}{l}\text { Method } \\
\text { of preparation }\end{array}$ & Size & $\begin{array}{l}\text { Route } \\
\text { of administration }\end{array}$ & Mode of action & Ref \\
\hline $\begin{array}{l}\text { DPPC, cholesterol and } \\
\text { stearylamine }\end{array}$ & CAT or SOD & $\begin{array}{l}\text { Reverse-phase evapora- } \\
\text { tion }\end{array}$ & - & Intravenous & $\begin{array}{l}\text { Decrease lipid per- } \\
\text { oxidation products } \\
\text { (malondialdehyde, } \\
\text { conjugated dienes, } \\
\text { lipid hydroperoxides) }\end{array}$ & [93] \\
\hline DPPC & a-Tocopherol & $\begin{array}{l}\text { Reverse-phase evapora- } \\
\text { tion }\end{array}$ & $320 \pm 40 \mathrm{~nm}$ & Intratracheal & $\begin{array}{l}\text { Reduce myeloper- } \\
\text { oxidase activity and } \\
\text { reverse of phorbol } \\
\text { myristate acetate- } \\
\text { induced changes in } \\
\text { lung edema, lipid } \\
\text { peroxidation, enzyme } \\
\text { and alkaline phos- } \\
\text { phatase activities }\end{array}$ & [94] \\
\hline DPPC and cholesterol & $\mathrm{Cu}, \mathrm{Zn} \mathrm{SOD}$ and CAT & $\begin{array}{l}\text { Reverse-phase evapora- } \\
\text { tion }\end{array}$ & $200 \mathrm{~nm}$ & $\begin{array}{l}\text { Intratracheal, instil- } \\
\text { lation }\end{array}$ & $\begin{array}{l}\text { Increase antioxidant } \\
\text { activity of alveolar } \\
\text { type II cell, increase } \\
\text { lung antioxidant } \\
\text { enzyme levels }\end{array}$ & {$[95,96]$} \\
\hline DPPC & SOD and/or CAT & $\begin{array}{l}\text { Reverse-phase evapora- } \\
\text { tion }\end{array}$ & $0.1-0.4 \mu \mathrm{m}$ & Intratracheal & $\begin{array}{l}\text { Prevent the chronic } \\
\text { vascular and paren- } \\
\text { chymal damage due } \\
\text { to oxygen toxicity }\end{array}$ & [97] \\
\hline DPPC & NAC & $\begin{array}{l}\text { Reverse-phase evapora- } \\
\text { tion }\end{array}$ & - & Intratracheal & $\begin{array}{l}\text { Increase pulmonary } \\
\text { glutathione }\end{array}$ & [98] \\
\hline DPPC & $\begin{array}{l}\text { NAC, glutathione, } \\
\text { a-tocopherol }\end{array}$ & $\begin{array}{l}\text { Thin-film hydration } \\
\text { method }\end{array}$ & $100 \mathrm{~nm}$ & Intratracheal instillation & $\begin{array}{l}\text { Reduce CINC-1, IL-1 } \beta \text {, } \\
\text { and TNF- } \alpha\end{array}$ & [99] \\
\hline $\begin{array}{l}\text { Phospholipid and } \\
\text { cholesterol }\end{array}$ & NAC & $\begin{array}{l}\text { Reverse phase evapora- } \\
\text { tion and spray drying }\end{array}$ & $\sim 100 \mathrm{~nm}$ & Inhalation & $\begin{array}{l}\text { Against TBARS produc- } \\
\text { tion }\end{array}$ & [100] \\
\hline DPPC & a-Tocopherol & $\begin{array}{l}\text { Solvent evaporation } \\
\text { method }\end{array}$ & - & $\begin{array}{l}\text { Intraperitoneal, injec- } \\
\text { tion }\end{array}$ & $\begin{array}{l}\text { Reduce acute inflam- } \\
\text { matory, cell influx and } \\
\text { suppress collagen } \\
\text { formation in lung } \\
\text { tissue }\end{array}$ & [101] \\
\hline $\begin{array}{l}\text { Chitosan, hyaluronan, } \\
\text { and phospholipids }\end{array}$ & Curcumin & Sonication, stirring & $130 \mathrm{~nm}$ & A549 cells & $\begin{array}{l}\text { Cell relative metabolic } \\
\text { activity } \geq 80 \% \text { after } \\
\text { treated with hydro- } \\
\text { gen peroxide }\end{array}$ & [102] \\
\hline
\end{tabular}

DPPC: L-a-dipalmitoylphosphatidyl-choline; NAC: $\mathrm{N}$-acetylcysteine; TBARS: thiobarbituric acid reactive species

Table 3 lists relevant studies focused on nanoparticlebased therapy for COPD.

\section{Solid lipid nanoparticles}

Solid lipid nanoparticles (SLNs) are biocompatible and markedly more stable than liposomes. Their production can be easily scaled up (high-pressure homogenisation and simple emulsification); and they are innocuous compared to polymeric nanoparticles. Castellani et al. prepared a SLNs based DDS using a melt-emulsion method to encapsulate proanthocyanidins and that showed it lowered oxidative stress by reducing ROS production. SLNs demonstrated non-significant toxicity against airway epithelial cells. The uptake and persistence of SLNs in airway epithelial cells in vitro were more extensive compared to free drugs and demonstrated prolonged residence time when administered in vivo. SLNs were taken up in a dose-dependent manner and persisted in cells up to 16 days. Further, SLNs were stable at $4{ }^{\circ} \mathrm{C}$ in double-distilled water for up to 2 months [109]. Carvalho et al. prepared SLNs containing carvacrol using a fusion-emulsification method. The polydispersity index (PDI) of the products was $0.126 \pm 0.015$ and the average size of SLNs was $78.72 \pm 0.85 \mathrm{~nm}$. SLNs containing carvacrol minimised the inhalation injury by significantly reducing malondialdehyde levels and minimized the histological changes [110]. 


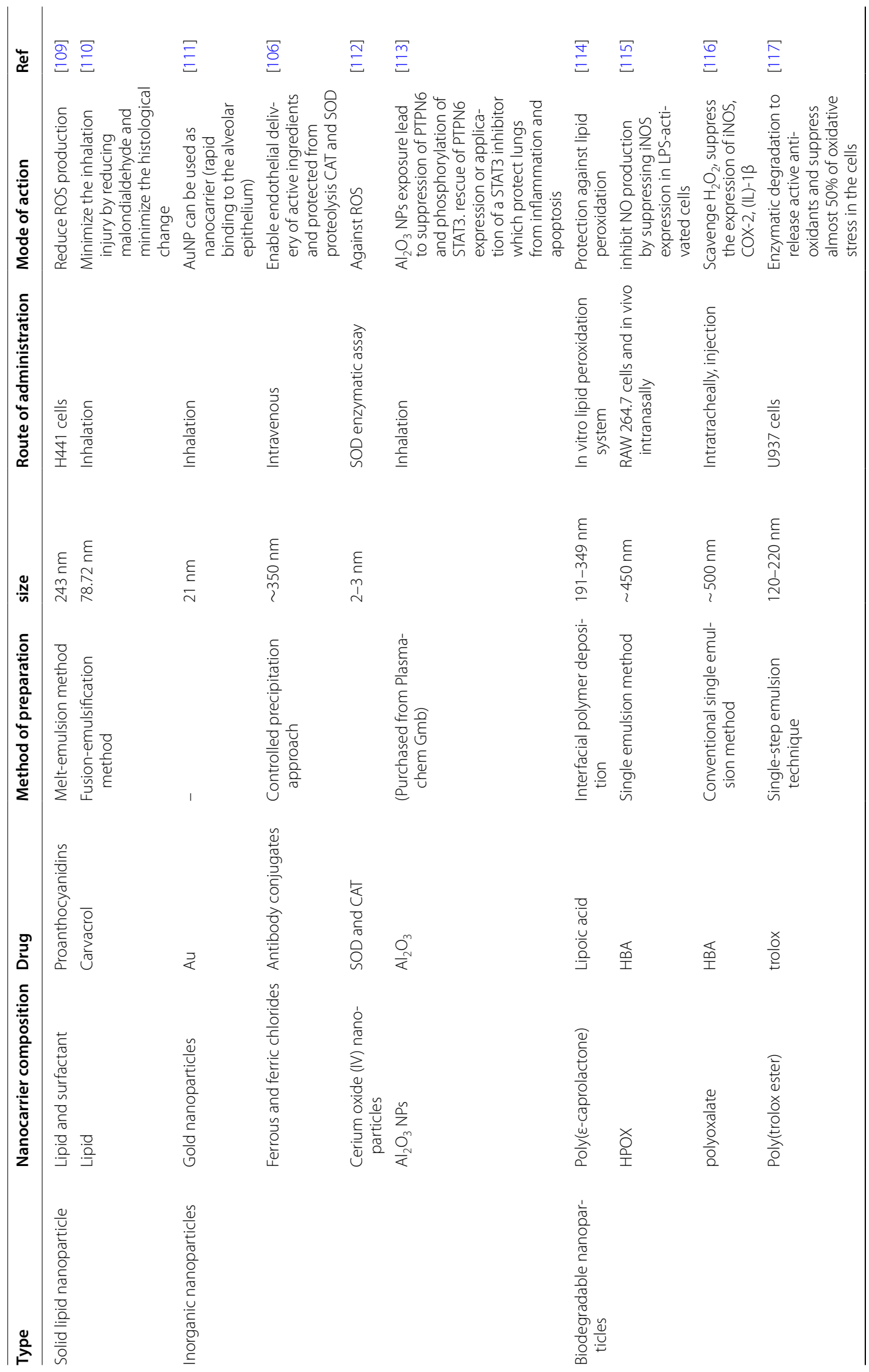




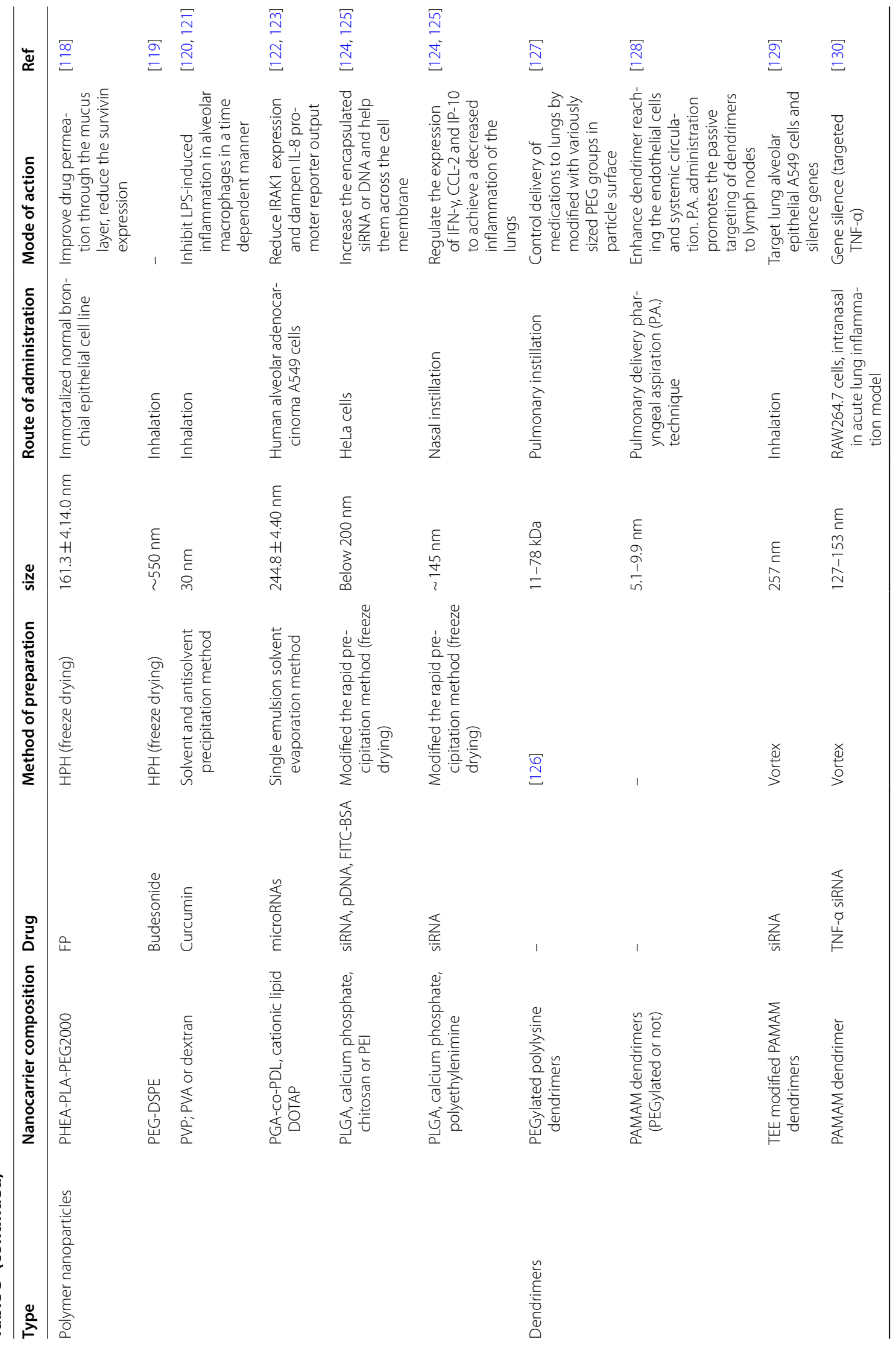




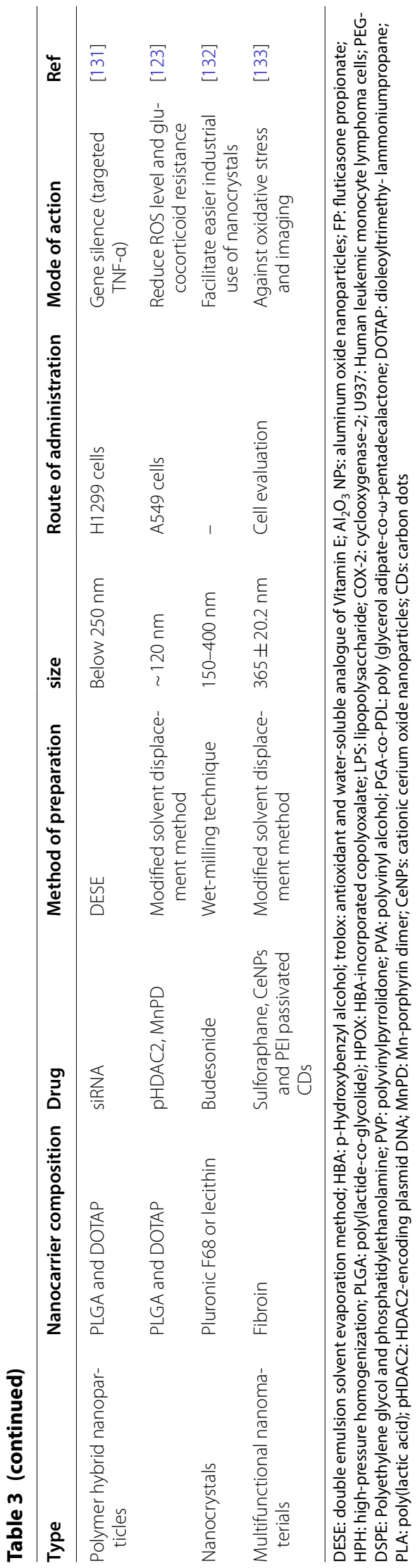


However, SLNs have several limitations concerning their application, including unpredictable drug-release behaviour and the potential for gelation owing to the polymorphism of solid lipids $[134,135]$.

\section{Inorganic nanoparticles}

Inorganic nanoparticles are composed of noble metals such as gold and silver or inorganic materials such as calcium phosphate, carbon, silicon oxide, and iron oxide. Inorganic nanoparticles generally possess versatile properties suitable for pulmonary delivery including wide availability, rich functionality, good biocompatibility, and potential capability of targeted delivery. Inorganic nanoparticles have also been assessed as potential nanocarriers for COPD. For example, cationic metallic nanoparticles are being used for gene delivery because they can easily bind to anionic DNA/RNA [136]; gold nanoparticles can be used for targeted delivery to epithelial cells in COPD [111]. Hood et al. described antibody conjugates loaded with ferrous and ferric chloride antioxidant nanoparticles for endothelial targeting which could target the endothelial delivery of CAT and SOD. These inorganic nanoparticles protected from proteolysis CAT and SOD and enabled endothelial active delivery, which provided specific protective antioxidant and antiinflammatory effects in animal models of acute inflammation and/or oxidative stress [106]. Gil et al. introduced inorganic cerium oxide (IV) nanoparticles conjugated with the antioxidative enzymes, SOD and CAT, to scavenge oxygen and nitrogen radicals. The results showed that SOD/CAT and the nanocarrier could complement each other and provide a synergetic antioxidant activity. Nonetheless, this approach needs to be explored further in in vivo studies [112]. Antioxidant enzyme nanocarrier formulations can be used to target endothelial cells to generate anti-inflammatory effects.

Inorganic nanoparticles exhibit intrinsic oxidant-generating properties. Some silver nanoparticles were found to induce oxidative stress in a dose- and time-dependent manner, as indicated by the depletion of GSH and induction of ROS, SOD, and CAT $[137,138]$. Avoiding the oxidation of nanoparticles is the most important aspect in the design of antioxidant inorganic nanoparticles.

\section{Polymeric nanoparticles}

Polymeric nanoparticles have an adaptable nature with physicochemical qualities that can change to accommodate different purposes. Different polymers can be used to reduce dosing frequency and target specific cells or organs, adjust the release pattern, and adjust the particle size and surface charge to escape alveolar macrophage clearance or facilitate transepithelial transport. The commonly used polymeric materials include natural polymers such as albumin, chitosan, gelatin and HA; synthetic polymers such as PEG, PVA, PLA; and copolymers, such as PLGA. Moreover, it has been recognised that polymers usually do not induce a strong immune response [139]. Mohamed et al. used PGA-co-PDL and DOTAP to prepare nanoparticles loaded with miR146a to reduce the expression of the IRAK1 target gene. miR146a delivered as miR-146a-NPs reduced the IRAK1 expression to $40 \%$ and dampened the IL-8 promoter-reporter output. These results demonstrate the potential of PGA-co-PDL NPs as a delivery system for miR-146a to treat COPD [122]. By transforming polymer nanoparticles into microparticles via spray drying, researchers have demonstrated the potential of transforming polymer nanoparticles into industrial preparations.

The development of a biodegradable NP-based DDS further optimize the application of polymeric nanoparticles as they can effectively avoid the accumulation of polymeric materials following repeated dosing. CS, HA, and PLGA have been frequently reported to have promising prospects. Biodegradable hydroxybenzyl alcohol-incorporated polyoxalate (HPOX) is a novel biodegradable nanoparticle material used to combat oxidative stress in airway inflammatory diseases. During the degradation of peroxalate ester linkages, HPOX leads to the releases of HBA in vitro. HPOX administered intranasally induces a significantly reduced expression of iNOS and attenuates allergic inflammation. No cytotoxicity was observed with cells treated with HPOX nanoparticles less than $100 \mu \mathrm{g}$ [115]. Biodegradable nanoparticles includes PLGA and PEG which enable the biodegradation of nanoparticles after administration [140, 141]. Further advancements have made by using biodegradable polymeric hydrogel for pharmacological applications. For example, sodium alginate (ALG)-Fe has tissue-mimicking, mechanical properties and biocompatibility [142].

Biodegradability and biopersistence of nanoparticles can influence nanoparticle-cell interactions, which may have direct effects on cellular or organelle oxidative status, or indirect effects through inflammatory processes and enzymatic detoxification pathways [143, 144]. Although the introduction of biodegradation provides opportunities to overcome airways defence and avoid the accumulation of polymeric materials, it has potential safety issues in other aspects. For example, the complete degradation of PLGA take months. The degradation products, lactic acid and glycolic acid, can accumulate and cause changes in a disturbance in the microenvironmental pH [145]. Therefore, it is highly recommended to determine the polymer degradation rate and long-term safety before inhaled polymeric DDS are used clinically. 


\section{Dendrimers}

Dendrimers represent a promising class of nanocarriers for drug delivery to the lungs. The commonly used polymeric materials include natural polymers, such as poly(amidoamine) (PAMAM), ploy( ${ }_{\mathrm{L}}$-lysine) (PLL), polyamides, polyesters (PGLSA-OH), polypropylenimine (PPI), ploy (2,2-bis(hydroxyl methyl) propionic acid), and ployethers [146]. PEGylated dendrimers have been used to reduce toxicity, improve pharmacokinetic profiles, and improve aqueous solubility. The degree of PEGylation can significantly effect dendrimer splitting and retention. Ryan et al. examined the potential utility of PEGylated poly(lysine) dendrimers as pulmonary delivery agents. Larger PEGylated dendrimers may be retained in the lungs and enable controlled drug delivery [127]. Zhong et al. investigated the systemic and lung cellular biodistribution of generation 3, PAMAM dendrimers (G3NH2) [128]. PAMAM dendrimers prolonged systemic circulation and accumulated effectively in the lungs through passive circulation. PAMAM dendrimers also show potential in delivering biomacromelucles, such as siRNA $[129,130]$.

\section{Lipid-polymer hybrid nanoparticles}

Lipid-polymer hybrid nanoparticles (LPNs) exhibit complementary characteristics of both polymeric nanoparticles and liposomes, particularly in based on their physical stability and biocompatibility. LPNs have been demonstrated to exhibit superior efficacy for in vivo cellular delivery. Thanki et al. developed lipidoid-modified (lipid like materials) LPNs consisting of PLGA and lipidoid. Lipidoid-modified LPNs showed strong gene silencing effects in the human non-small lung carcinoma cell line H1299 [131]. Lipidoid-modified LPNs offer promising prospects for the efficient and safe intracellular delivery of siRNA for COPD [147]. Lipidoid consist of an alkylated tetraamine backbone. Different analogues have been obtained, depending on the degree of alkylation. Compared to the commonly used cationic lipids such as DOTAP, lipidoids contain multiple secondary and tertiary amines. Therefore, they are more efficient in interacting with anionic siRNA molecules without significantly increasing the net charge of the LPNs. Another LPNs are a core-shell type LPNs composed of a PLGA core encapsulating a potent antioxidant Mn-porphyrin dimer (MnPD) and a cationic lipid (DOTAP) shell that binds the pHDAC2. The transfection of pHDAC2 combined with the elimination of ROS by MnPD exhibited a significant enhancement of intracellular HDAC2 expression levels, suggesting that the multi-antioxidative activity of MnPD plays a crucial role in the expression of HDAC2. The nanocarriers of LPNs are suitable for delivering drugs for COPD [123]. Efficient and simple large-scale production of nanoparticles has already been developed; however, attempts continue to scale-up the production of LPNs and simplify their preparation.

\section{Multifunctional nanoparticles}

Multifunctional nanomaterials integrating therapeutic and imaging modalities have opened a new era in the present therapeutic strategies, namely, theranostics. Two-dimensional (2D) nanosheets, a type of brand-new nanomaterial, which could integrates multiple functionalities of various materials to obtain an 'all-in-one' platform is a potential starting point for translational research [148]. Passi et al. designed a multifunctional silk fibroin-based carrier for the delivery of antioxidant and imaging agents. A one-step desolvation method was used to prepare sulforaphane (antioxidant drug)-loaded silk fibroin nanoparticles (SFSNPs). These anionic SFSNPs were further coupled with CeNPs and PEI-passivated carbon dots (CDs) to form self-assembled CeNP-CD@ SFSNPs nanocomposites. The synthesised CeNP-CD@ SFSNPs nanocompositescould could efficiently reduce ROS levels while simultaneously enabling imaging of the cells [133]. Such multifunctional nanocomposites could be potential candidates for the delivery of drugs to prevent oxidative stress, simultaneously, enabling the detection of pathological conditions in patients.

Nanotechnology provides a new dimension to the targeted drug-delivery approach, with multiple benefits in COPD. However, nanomaterials for transporting therapeutics need to be assessed for the potential health hazards, especially since different nanoparticles have been demonstrated to induce toxicity related to their nanometre size, opening a the new field of nanotoxicology [149]. Nanoparticles also generate and contribute to oxidative stress via direct and indirect cellular interactions. Nanoparticle interaction and damage to internal cellular structures can lead to oxidation, which further exacerbate the severity of oxidative stress. Additionally, nanoparticles may indirectly interact with cells to alter ROS production and emission through modified cellular phagocytic activity and oxidative burst. Liu et al. evaluated the oxidative stress caused by silica nanoparticles $\left(\mathrm{SiO}_{2} \mathrm{NPs}\right)$. The fluorescent probe, DCFH-DA, was used to detect ROS by measuring the fluorescence intensity. Interestingly, the fluorescence was about 1.7 times stronger in cells exposed to $\mathrm{SiO}_{2}$ NPs than in those exposed to microsized $\mathrm{SiO}_{2}$ particles. The finding suggested that the oxidative damage in cells exposed to $\mathrm{SiO}_{2} \mathrm{NPs}$ was more serious than that in A549 cells exposed to microsized $\mathrm{SiO}_{2}$ [150]. This is because $\mathrm{SiO}_{2}$ NPs have a smaller size 
and larger surface area, which can more efficiently interact with cellular or subcellular structures. However, there is an overwhelming amount of toxicity data derived from environmental health studies, which shows that nanoparticles can induce oxidative stress. Whether the results apply to nanoparticle therapeutics remains controversial. The induced toxicity and oxidative stress of nanoparticles must be considered when designing nanoparticles for the treatment of oxidative stress-induced COPD.

Nanoparticle technology offer effective approach for drug delivery in COPD. However, several issues remain to be resolved prior to its use in a clinical setting. To date, no clinical studies using nanoparticles in the treatment of oxidative stress have been registered at the 'clinical trials.gov' database. Inhaled pharmacologic therapy is a cornerstone of treatment for patients with COPD, which have a wide range of advantages such as requirement of low concentrations of drug to reach therapeutic efficacy, surpassing first pass metabolism and a very low incidence of side effects. From an aerodynamic viewpoint, nanoparticles cannot be directly used for inhalation because they are not in the optimal size range for inhalation (ideal median mass aerodynamic diameter (MMAD) for deposition in the small airways and alveoli of the lungs should be 1 to $5 \mu \mathrm{m}$ ). Individual nanoparticles used for inhalation are prone to exhalation instead of deposition in deep lung owing to the low inertia of nanoparticles. Additionally, nanoparticles have larger surfaces, which results in an increase their free energy and increased the interaction between particles. The high degree of interaction between nanoparticles leads to particle agglomeration or drug-crystal growth $[151,152]$. To address these problems, nanoparticles should be entrapped within microparticles. The solid matrix can prevent the interaction between nanoparticles, limit their mobility, and increase their long-term stability. More importantly, it can improve aerosolization properties and improve pulmonary administration.

\section{Microparticles}

Microparticles are rapidly gaining popularity owing to their controlled-release properties, high drug loading and entrapment efficiencies, particle size, therapeutic benefits, and compatibility, among other advantages. In particularly, the delivery of microparticles via inhalation is becoming an area of remarkable interest for researchers in the field of respiratory medicine [153].

Microparticle inhalers have become increasingly attractive for the pulmonary delivery of locally and systemically effective medications. Dry powders show appropriate morphologies and suitable aerosol properties for inhalation drug delivery. Manufacturing methods including jet milling, spray drying, spray freeze drying and supercritical fluid (SFD) technology are capable of generating particles ranging from 1 to $5 \mathrm{um}$ in size and have been used to prepare dry powders with desired properties. Depending on the particle size, microparticles are deposited in the lungs via the three mechanisms, namely, gravitational sedimentation, inertial impaction, and Brownian diffusion (Fig. 4). As particles with larger diameters (usually $>10 \mu \mathrm{m}$ ) are suitable for deposition in the oropharynx and those with smaller diameters (usually $<0.5 \mu \mathrm{m}$ ) are easily exhaled, microparticles in the range of 1 to $5 \mu \mathrm{m}$ are optimal for achieving effective pulmonary deposition. This phenomenon is referred to as an impaction; particles with aerodynamic diameters between approximately 1 and $5 \mu \mathrm{m}$ are deposited slowly in the narrow airways and bronchioles by sedimentation [154]. In addition to particle size, other properties influence aerosol performance, namely, particle density, shape, crystallinity and polymorphism, inter-particulate forces and surface roughness [155].

Relevant studies focusing on microparticles for oxidative stress are summarized in Table 4.

\section{Microscale powders}

Microscale dry powder Advanced particle engineering design technology has been used to prepare inhalable microscale powders. The representative image of microscale dry powder can be seen from Fig. 5A. Muralidharan et al. reported the treatment of pulmonary inflammation by inhalation of microparticulate powders with dimethyl fumarate, an antioxidant Nrf2 activator. The spray-dried and co-spray-dried particles were prepared by advanced spray drying of an organic solution in a closed mode and employing D-mannitol as an aerosol performance enhancer. The dried powder had high drug loading with good in vitro aerosol dispersion performance. Spraydried mannitol has a MMAD of $0.56 \mu \mathrm{m}$ and a fine particle fraction (FPF) of $49 \%$. Using in vitro studies of lungdeposition model, studies reported that aerosol particles can reach the lower pulmonary tract and treat inflammation during COPD [159]. A similar co-spray dried powder was described by Trotta et al. In their study, inhalable microparticles containing BD and RES were prepared and characterised to develop a multi-drug inhalable formulation with antioxidant and anti-inflammatory activities for the treatment of COPD [162]. The preparation of microscale powder is simple and easy to scale-up; however, drug loading and short duration of action are commonly encountered challenges [179].

Porous microparticles The short systemic circulation time of microparticles remains a challenge owing to the rather short duration of action [6,7]. Aerosolization of particles is an important property for inhalation and 


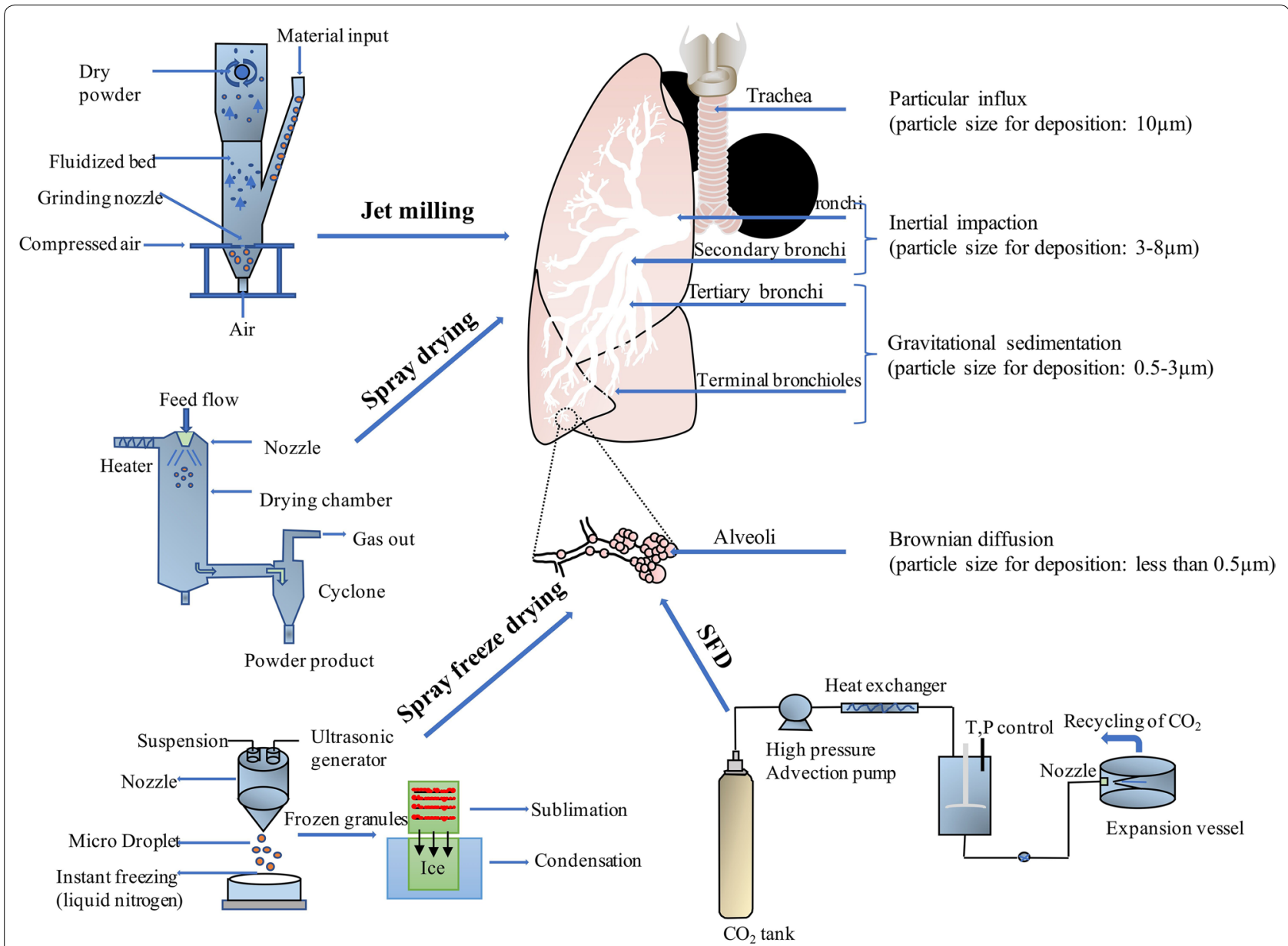

Fig. 4 Manufacturing methods, jet milling, spray drying, spray freeze drying and SFD, of preparing microparticles and their deposition mechanism

depends on particle-particle and particle-wall interactions. Microparticles with pores have a lesser tendency to aggregate, exhibit decreased phagocytosis by alveolar macrophages, and have higher aerosolization efficiency (Fig. 5B). The most widely exploited method for preparing porous microparticles is the multiple emulsion (w/o/w) approach with a porosity-inducing agent (such as $\beta$-cyclodextrin). Zhang et al. developed BD-loaded large porous microparticles (LPPs) for inhalation. The optimised formulation showed desirable aerodynamic behaviour to allow for drug delivery to the lungs [170]. Porous microparticles can also be used to load other types of antioxidative drugs for COPD. Many new materials have also been used for the preparation of porous particles because of their excellent biocompatibility, biodegradable and other properties. Jeong et al. developed a new family of biodegradable polymers, vanillyl alcohol-containing copolyoxalate (PVAX), which could scavenge hydrogen peroxide and exert potent antioxidant and anti-inflammatory effects. PVAX microparticles reduced oxidative stress and suppressed the expression of pro-inflammatory TNF- $\alpha$ and iNOS. Porous PVAX microparticles with encapsulated dexamethasone show great potential as a therapeutic system to treat airways inflammatory diseases [114]. However, PVAX microparticles have a large diameter $(13 \mu \mathrm{m})$, which can negatively influence the deposition into the deep lungs if administrated by inhalation. Porosity $\backslash$ makes large-scale manufacturing difficult, and the requirement of particle flow-ability increases the difficulty in designing microparticles. Therefore, more innovation is needed to generate new pharmaceuticals for this market.

Mucoadhesive microparticles To prolong drug action in the lungs, mucoadhesive polymers have been explored for COPD. Mucoadhesive polymers have structures and functional groups with high affinity for mucosal surfaces. For example, amino groups in chitosan undergo electrostatic interactions with the anionic groups of the mucus, which increases the mucoadhesiveness of micro- 


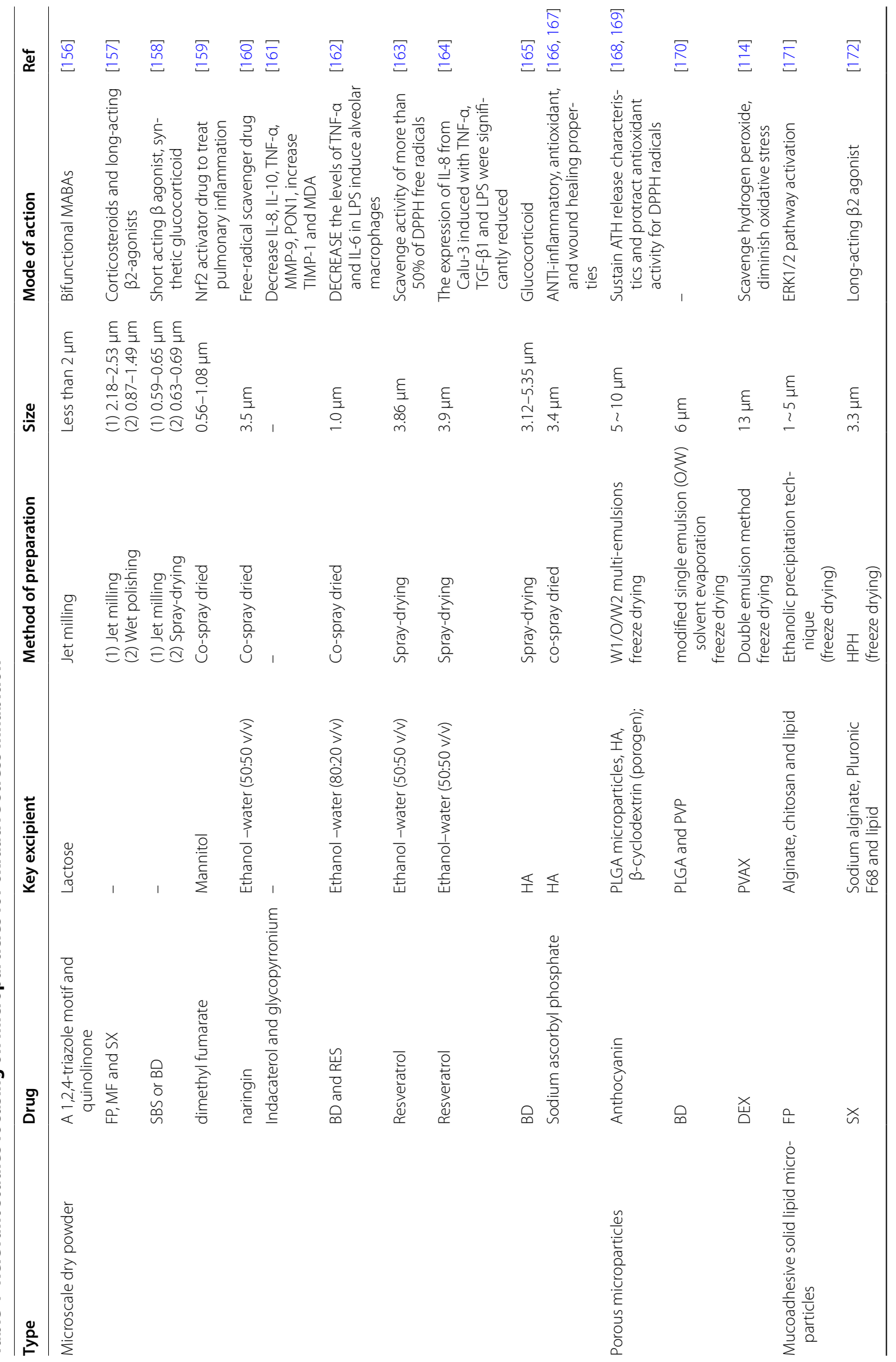




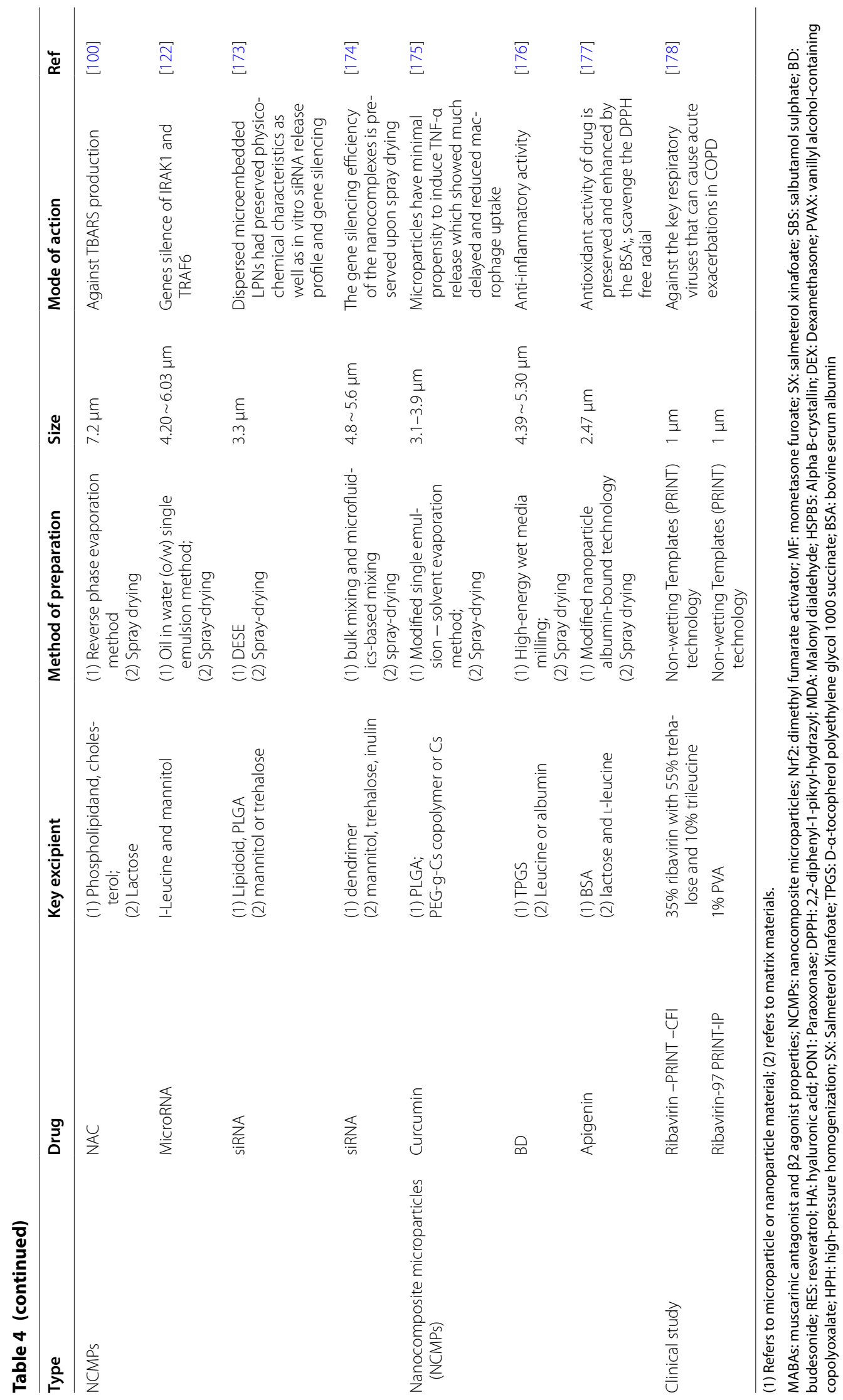



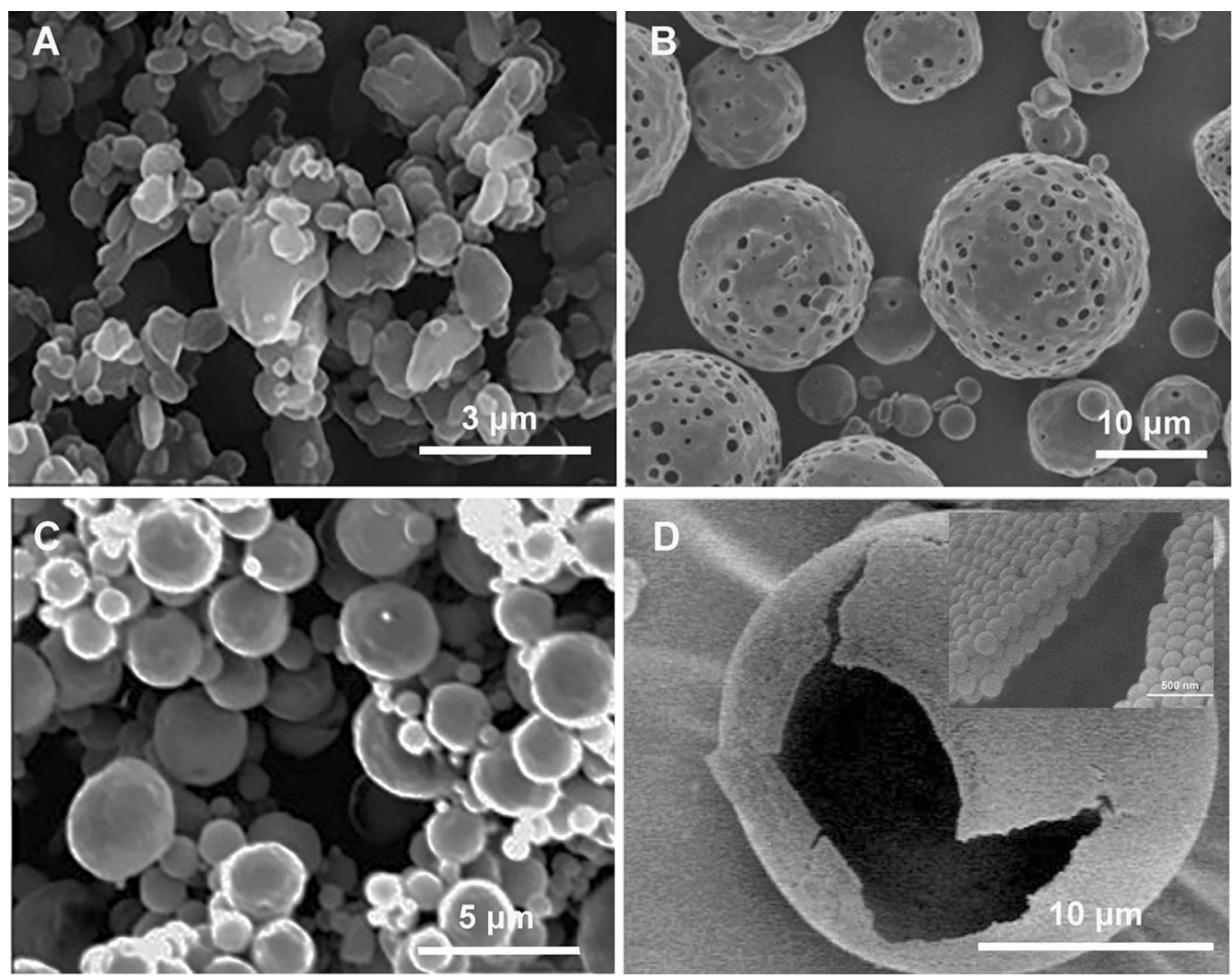

Fig. 5 Morphology of A microscale dry powder [180]; B porous microparticles [170]; C matrix NCMPs [181]; D hollow NCMPs [182]

particles. Anionic alginate can form hydrogen bonds with the mucin layer of the mucosa [183]. Solid lipid microparticles (SLMs) have a strong ability to form hydrogen bonds with the mucin layer of the mucosa to control drug release. The therapeutic approach using FP-loaded microparticles offers a remarkable potential for the treatment of COPD. Amore et al. described alginate- and chitosanbased mucoadhesive SLMs for the effective delivery of fluticasone propionate to treat COPD. SLMs have a useful dimensions (MMAD is 3.5-4.0 $\mu \mathrm{m}$ ) for pulmonary release of FP to the secondary bronchi [171]. Liu et al. prepared budesonide mucoadhesive microparticles containing hyaluronic acid by spray drying. The MMAD of microparticles was $3.12-5.35 \mu \mathrm{m}$, which was in the inhalable range; however, the FPF was $35.6 \%$ which had to be further improved. The study showed that budesonide loaded in the mucoadhesive microparticles exhibited a significantly prolonged $\mathrm{T}_{\max }$, which substantially delayed absorption and prolonged the retention of budesonide. This resulted in an increased bioavailability in an animal model owing to the mucoadhesive ability of hyaluronic acid [165]. Despite the success of mucoadhesive microparticles for the pulmonary delivery of antioxidant drugs, the release pattern and drug encapsulation efficiency should be con- sidered when using microparticles. The redispersion of mucoadhesive microparticles is not feasible and should be evaluated before administration.

\section{Nanocomposite microparticles}

Nanocomposite microparticles in research Studies combining the merits of nanoparticles with the delivery convenience have been conducted by spray drying nanoparticles with or without additional excipients; the particles obtained using this approach are termed nanocomposite microparticles (NCMPs), which have the advantage of both nanoparticles and microparticles. The represent image of NCMPs can be seen from Fig. 5C, D. Under physiological conditions, NCMPs disassociate into the original nanoparticles and maintain the properties of the nanocarriers (nano complexes or nanoparticles), including their drug release and delivery advantages (Fig. 6). NCMPs exhibit better in vitro antioxidant activity than microparticles containing the non-encapsulated drug, which makes it a good candidate for the treatment of oxidative stress [100, 184]. Most of the NCMPs were synthesised using non-water-soluble or biodegradable polymers to atomise the aqueous suspension. Such microparticles can maintain the structure of nanoparticles after the drying 


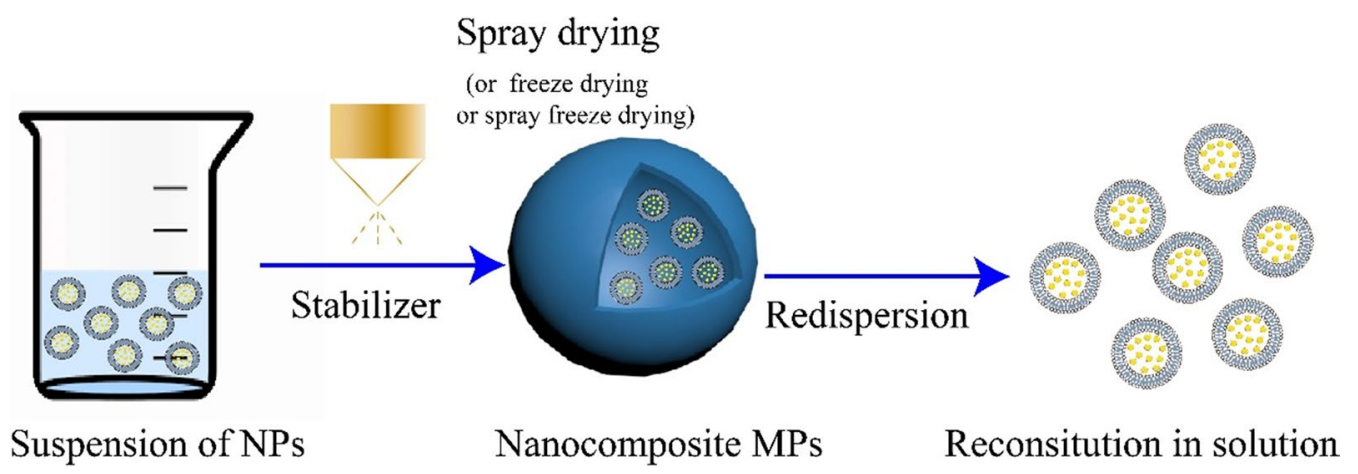

Fig. 6 Preparation of nanocomposite microparticle and their reconstitution

process and translate into inhalable microparticle powder, which is more suitable for the treatment of COPD. NAC was efficiently encapsulated in liposomes produced by the reverse-phase evaporation method. Powders containing these liposomes presented suitable properties for pulmonary administration. A MMAD of $7 \mu \mathrm{m}$ and respirable fraction above $30 \%$, maintained or increased antioxidant activity after the drying process and recovered nano sized liposomes after aqueous redispersion. NAC dry powder possessed a higher antioxidant activity than the non-encapsulated drug in solution or dry powder containing the non-encapsulated NAC [100]. Mohamed et al. prepared NCMPs of microRNA (miR-146a) containing PGA-co-PDL nanoparticles for dry powder inhalation using $\mathrm{L}$-leucine and mannitol as excipients. The microparticles maintained the bioactivity of miR-146a; however, after dispersion, the nanoparticles size increased, from $244.8 \pm 4.40 \mathrm{~nm}$ to $409.7 \pm 10.05 \mathrm{~nm}$ [122]. The microparticles showed a high FPF of $51.33 \%$ and MMAD $\leq 5 \mu \mathrm{m}$ suggesting that deposition in the respirable region of the lungs would be possible. The selection of excipients and drying parameters is crucial for maintaining the least change in nanoparticles. In vitro drug release from microparticles depends on drug concentration in the nanoparticles, morphology of the final carrier, and the presence of pharmaceutical adjuvants $[185,186]$. Generally, studies with NCMPs using drug-loaded nanoparticles aim to achieve a stable formulation with cellular uptake, long tissue retention times and sustained drug release. NCMPs are a promising approach for pharmaceutical nanoparticle processing and novel drug-delivery platforms.

To better control drug release, drug-loaded nanoparticles embedded within swellable microparticles represent another promising approach for drug delivery to the alveolar region where macrophage clearance occurs. Sherbiny and Smyth developed curcumin-loaded PLGA nanoparticles with chitosan-grafted-PEG or chitosan using spray drying. This process resulted in a series of respirable amphiphilic hydrogel microparticles derived by adjusting the PLGA content. The PLGA nanoparticles and the hydrogel microspheres showed sizes ranging from $221-243 \mathrm{~nm}$ and 3.1-3.9 $\mu \mathrm{m}$, respectively. Hydrogel microparticles had desirable biodegradation rates, high drug loading (up to 97\%), and good sustained release. Hydrogel microparticles had a minimal propensity to induce TNF- $\alpha$ release and showed delayed and reduced macrophage uptake [175]. These studies revealed that swellable microparticles could used as potential carriers for sustained pulmonary drug delivery. Current research on swellable microparticles for antioxidant delivery is still in its infancy. However, the key requirement of NCMPs is the spontaneous release of unaffected nanoparticles following pulmonary deposition. The in vitro and in vivo release patterns of swellable microparticles should be considered before further investigation.

Considerations in translating of NCMPs to the clinic The lung itself is an extremely complex structure, functioning as a significant barrier protect the respiratory system from pollutant particles and microorganisms. Many of the processes associated directly with respiratory functions present significant challenges for particle deposition, such as air humidification, temperature control in the thoracic and tracheobronchial regions, and gas exchange in the alveolar-interstitial region. Thus, particles must overcome lung-geometry barriers as well as lung physiology with high humidity (around 90\%) during the respiratory phase, which can interfere with particle size and deposition. Particles must avoid mucociliary clearance and overcome the pulmonary surfactant layer that covers the alveolar epithelium in deep lungs. The fate of NCMPs includes the following three processes: First, the NCMPs need to translocate across the lung barrier and reach the bloodstream; NCMPs associate with the lining fluid or cells and are thus retained in the lungs for a long time; they are phagocytosed by macrophages. Overall, depending 


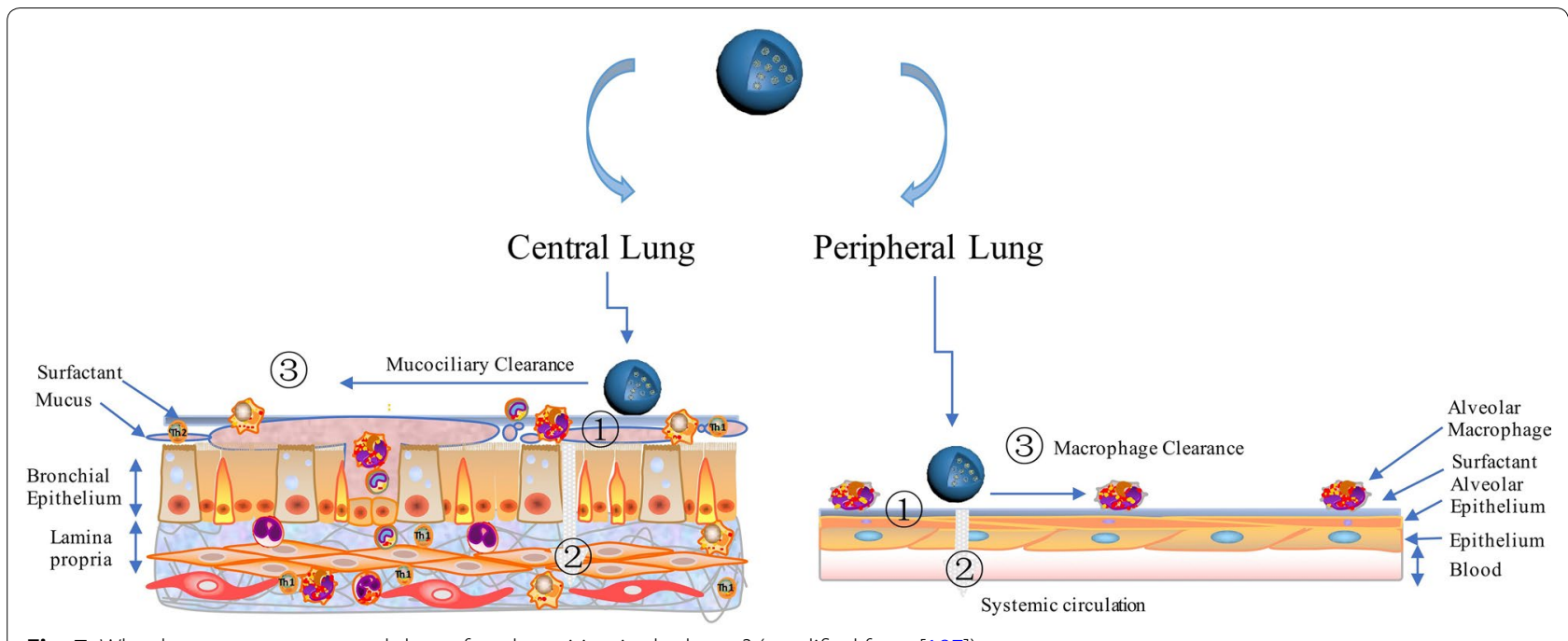

Fig. 7 What happens to an aerosol drug after deposition in the lungs? (modified from [187])

on the final particle destination, epithelial tight junctions, immunological cells, and lung lining fluids that represent additional barriers that must be overcome (Fig. 7).

\section{Inhalable microparticles in clinical applications}

Inhalable microparticles can be used to treat oxidative stress in COPD. Newly investigated inhalable microparticles are currently under clinical study. Dumont et al. used the Particle Replication In Non-wetting Templates (PRINT) technology to produce dry powder microparticles with uniform shape and size which is currently under Phase 1 study. Two new inhaled formulations of ribavirin (Ribavirin-PRIN-CFI and Ribavirin-PRINT-IP) were developed to achieve efficient delivery to the lung and minimise bystander exposure [178].

Therapies against oxidative stress and anti-inflammatory drugs are the mainstay treatments for COPD. However, frequent drug administration is associated with potential side effects. Thus, to ensure that drugs are administered less often, effective and safe sustained release drugs from of biodegradable microparticles is required for pulmonary delivery.

\section{Conclusion and future perspectives}

Oxidative stress plays a major role in the pathogenesis and progression of COPD. It can cause airway inflammation, which further contributes to the oxidative burden. Although the mechanisms of airway inflammation and oxidative stress in COPD are apparent, the lack of an efficient DDS causes improper treatment that leads to chronic and fatal lung pathophysiology. There is an immediate need to develop novel DDS that can effectively deliver COPD therapeutics. The findings presented in this review suggest that nano/microtechnologybased therapeutics can be a more effective approach to treat oxidative stress. DDS have their advantages and disadvantages. Identification of the ideal nanoparticles properties is essential before making nanoparticles into microparticles to elicit the desired response and to acquire in-depth knowledge of the molecular and cellular mechanisms of oxidative stress in COPD. Liposomes are composed of biodegradable ingredients. They are easy to prepare, nonimmunogenic and show good aerosolization in solid form. However, there are also some requirements (mucus barrier, aerodynamic properties, clearance mechanism, absorption, and release properties) to be fulfil prior to clinical. SLNs (or nanostructured lipid carriers (NLC) improve drug retention and prolong drug release. For dendrimers and multifunctional nanoparticles, understanding the manufacturing and control requirements is very important. LPPs and NCMPs, such as LPNs, polymer nanoparticles, or biodegradable nanoparticle-loaded microparticles maybe the best option in COPD to prevent oxidative stress. However, despite some encouraging results, the clinical use of nano/microparticles in the pulmonary field is still in the early stages. More research is needed to achieve efficient delivery of antioxidants to the lungs. Most importantly, potential lung toxicity (e.g., those caused by inorganic nanoparticles) and particle interaction with the immune systems could be risk factors that are far more severe than inflammation in COPD. Carefully designed preclinical studies on the safety and efficacy will help to move the nano/ micro technology-based therapeutics closer to clinical evaluation in human subjects. 


\begin{abstract}
Abbreviations
COPD: Chronic obstructive pulmonary disease; DDS: Drug delivery system; ROS: Reactive oxygen species; RNS: Reactive nitrogen species; iNOS: Inducible nitric oxide synthase isoenzymes; PM: Particulate matter; SLPI: Secretory leukocyte protease inhibitor; a1 AT: Alpha-1-antitrypsin; IL: Interleukin; NF-kB: Nuclear factor kappa B; IL-8: Interleukin-8; GM-CSF: Granulocyte macrophage colony-stimulating factor; SOD: Superoxide dismutase; GPx: Glutathione peroxidase; iNOS: Inducible nitric oxide synthase; HDAC: Histone deacetylase; EGFRs: Epithelial growth factor receptors; BHR: Hyperresponsiveness; P13K: Phosphoinositide 3-kinase; TGF: Transforming growth factor; MMP: Matrix metalloproteinase; MUC5AC: Ne, neutrophil elastase; TNF: Tumor necrosis factor; CCL: CC-chemokine ligand; CCR: CC-chemokine receptor; CXCL: CXC-chemokine ligand; $C X C R$ : CXC-chemokine receptor; $T_{H} 1: T$ helper 1 cells; $\mathrm{T}_{C}$ 1: Type 1 cytotoxic; NO: Nitric oxide; ONOO- ${ }^{-}$Peroxynitrite; DPPC: L-adipalmitoylphosphatidyl-choline; CAT: Catalase; NAC: N-acetylcysteine; TBARS: Thiobarbituric acid reactive species; HBA: P-Hydroxybenzyl alcohol; Trolox: Antioxidant and water-soluble analogue of Vitamin $\mathrm{E}_{;} \mathrm{Al}_{2} \mathrm{O}_{3} \mathrm{NPs}$ : Aluminum oxide nanoparticles; FP: Fluticasone propionate; $\mathrm{HPH}$ : High-pressure homogenization; PLGA: Poly(lactide-co-glycolide); PEG-DSPE: Polyethylene glycol and phosphatidylethanolamine; PVP: Polyvinylpyrrolidone; PVA: Polyvinyl alcohol; PGA-co-PDL: Poly (glycerol adipate-co- $\omega$-pentadecalactone; DOTAP: Dioleoyltrimethy- lammoniumpropane; PLA: Poly(lactic acid); PEG: Polyethyleneglycol; pHDAC2: HDAC2-encoding plasmid DNA; MnPD: Mn-porphyrin dimer; DESE: Double emulsion solvent evaporation method; HPOX: HBA-incorporated copolyoxalate; LPS: Lipopolysaccharide; COX-2: Cyclooxygenase-2; U937: Human leukemic monocyte lymphoma cells; CeNPs: Cationic cerium oxide nanoparticles; CDs: Carbon dots; SLNs: Soild lipid nanoparticles; HPOX: Hydroxybenzyl alcohol-incorporated polyoxalate; LPNs: Lipid-polymer hybrid nanoparticles; $\mathrm{SiO}_{2} \mathrm{NPs}$ : Silica nanoparticles; MABAs: Muscarinic antagonist and $\beta 2$ agonist properties; MMAD: Median mass aerodynamic diameter; SFD: Supercritical fluid; NCMPs: Nanocomposite microparticles; MF: Mometasone furoate; SX: Salmeterol xinafoate; SBS: Salbutamol sulphate; Nrf2: Dimethyl fumarate activator 2; BD: Budesonide; RES: Resveratrol; HA: Hyaluronic acid; HSPB5: Alpha B-crystallin; DEX: Dexamethasone; PVAX: Polyvinyl alcoholcontaining copolyoxalate; HPH: High-pressure homogenization; SX: Salmeterol Xinafoate; FP: Fluticasone Propionate; TPGS: D-a-tocopherol polyethylene glycol 1000 succinate; BSA: Bovine serum albumin; FPF: Fine particle fraction; LPPs: Large porous microparticles; SLMs: Solid lipid microparticles; NCMPs: Nanocomposite microparticles; PRINT: Particle Replication In Non-wetting Templates.
\end{abstract}

\section{Acknowledgements}

Not applicable.

\section{Authors' contributions}

LS brought forward the subject and wrote the mechanisms of oxidative stress in COPD. YX guided the writing and wrote the following part. HL helped collect information for the subject. All authors participated in designing and revising the manuscript. All authors read and approved the final manuscript.

\section{Funding}

This work was funded by Bethune project of Jilin University, Grant Number 2018B10; by Education Department of Jilin Province, Grant Number JJKH20180193KJ; and by China Scholarship Council, Grant Number 201906210064.

\section{Availability of data and materials}

Not applicable.

\section{Ethics approval and consent to participate}

Not applicable.

\section{Consent for publication}

Not applicable.

\section{Competing interests}

The authors declare that they have no competing interests.

\section{Author details}

${ }_{1}^{1}$ Department of Respiratory Medicine, Key Laboratory of Organ Regeneration \& Transplantation of the Ministry of Education, The First Hospital of Jilin
University, Changchun 130061, People's Republic of China. ${ }^{2}$ Department of Pharmacy, Faculty of Health \& Medical Sciences, University of Copenhagen, 2100 Copenhagen, Denmark.

Received: 20 April 2020 Accepted: 7 October 2020

Published online: 19 October 2020

\section{References}

1. Qaseem A, Wilt TJ, Weinberger SE, et al. Diagnosis and management of stable chronic obstructive pulmonary disease: a clinical practice guideline update from the American College of Physicians, American College of Chest Physicians, American Thoracic Society, and European Respiratory Society. Ann Intern Med. 2011;155:179-91.

2. Angelis $\mathrm{N}$, Porpodis $\mathrm{K}$, Zarogoulidis $\mathrm{P}$, et al. Airway inflammation in chronic obstructive pulmonary disease. J Thorac Dis. 2014;6:S17-20.

3. Conde-Sampayo A, Lorenzo-Gonzalez M, Fernandez-Villar A, et al. Exposure to residential radon and COPD: a systematic review. Int J Chron Obstruct Pulmon Dis. 2020;15:939-48.

4. Joppa P, Petrášová D, Stančák B, et al. Oxidative stress in patients with COPD and pulmonary hypertension. Wien Klin Wochenschr. 2007;119:428-34.

5. Kluchova Z, Petrášová D, Joppa P, et al. The association between oxidative stress and obstructive lung impairment in patients with COPD. Physiol Res. 2007;56:51-6.

6. Rahman I, Gilmour PS, Jimenez LA, et al. Oxidative stress and TNF-a induce histone Acetylation and NF-KB/AP-1 activation in Alveolar epithelial cells: Potential mechanism In gene transcription in lung inflammation. Mol Cell Biochem. 2002;21:239-48.

7. Morcillo EJ, Estrela J, Cortijo J. Oxidative stress and pulmonary inflammation: pharmacological intervention with antioxidants. Pharmacol Res. 1999:40:393-404.

8. Sadeghi-Hashjin G, Folkerts G, Henricks P, et al. Peroxynitrite induces airway hyperresponsiveness in guinea pigs in vitro and in vivo. Am J Respir Crit Care Med. 1996;153:1697-701.

9. Krishna M, Madden J, Teran L, et al. Effects of 0.2 ppm ozone on biomarkers of inflammation in bronchoalveolar lavage fluid and bronchial mucosa of healthy subjects. Eur Respir J. 1998;11:1294-300.

10. Baker KE, Bonvini SJ, Donovan C, et al. Novel drug targets for asthma and COPD: lessons learned from in vitro and in vivo models. Pulm Pharmacol Ther. 2014;29:181-98.

11. Durham AL, Caramori G, Chung KF, et al. Targeted anti-inflammatory therapeutics in asthma and chronic obstructive lung disease. Transl Res. 2016;167:192-203.

12. Carvalho TC, Peters JI, Williams RO III. Influence of particle size on regional lung deposition-what evidence is there? Int J Pharm. 2011;406:1-10.

13. Burhan E, Ruesen C, Ruslami R, et al. Isoniazid, rifampin, and pyrazinamide plasma concentrations in relation to treatment response in Indonesian pulmonary tuberculosis patients. Antimicrob Agents Chemother. 2013;57:3614-9.

14. Ratemi E, SultanaShaik A, Al-Faraj A, et al. Alternative approaches for the treatment of airway diseases: focus on nanoparticle medicine. Clin Exp Allergy. 2016;46:1033-42.

15. Wadhwa R, Aggarwal T, Thapliyal N, et al. Nanoparticle-Based Drug Delivery for Chronic Obstructive Pulmonary Disorder and Asthma: Progress and Challenges Nanotechnology in Modern Animal Biotechnology. New York: Elsevier; 2019. p. 59-73.

16. Domej W, Oettl K, Renner W. Oxidative stress and free radicals in COPD - implications and relevance for treatment. Int J Chron Obstruct Pulmon Dis. 2014;9:1207.

17. Dua K, Malyla V, Singhvi G, et al. Increasing complexity and interactions of oxidative stress in chronic respiratory diseases: an emerging need for novel drug delivery systems. Chem Biol Interact. 2019;299:168-78.

18. Sethi GS, Dharwal V, Naura AS. Immunological basis of oxidative stressinduced lung inflammation in asthma and COPD, oxidative stress in lung diseases. Berlin: Springer; 2019. p. 195-223.

19. Yao H, Yang S-R, Kode A, et al. Redox regulation of lung inflammation: role of NADPH oxidase and NF-KB signalling. New York: Portland Press Ltd.; 2007. 
20. Pryor WA, Dooley MM, Church DF. Mechanisms of cigarette smoke toxicity: the inactivation of human a-1-proteinase inhibitor by nitric oxide/ isoprene mixtures in air. Chem Biol Interact. 1985;54:171-83.

21. Behrendt CE. Mild and moderate-to-severe COPD in nonsmokers: distinct demographic profiles. Chest. 2005;128:1239-44.

22. Song L, Li D, GuY, et al. Let-7a modulates particulate matter $(</=2.5$ mum)-induced oxidative stress and injury in human airway epithelial cells by targeting arginase. J Appl Toxicol. 2016;36: 1302-10.

23. Song L, Li D, Li X, et al. Exposure to PM25 induces aberrant activation of NF-kappaB in human airway epithelial cells by downregulating miR-331 expression. Environ Toxicol Pharmacol. 2017;50:192-9.

24. Gutieridge JM, Quinlan GJ, Yamamoto Y. Are fatty acid patterns characteristic of essential fatty acid deficiency indicative of oxidative stress? Free Radic Res. 1998;28:109-14.

25. Headlam HA, Davies MJ. Markers of protein oxidation: different oxidants give rise to variable yields of bound and released carbonyl products. Free Radic Biol Med. 2004;36:1175-84.

26. Liu Z, Zhou T, Ziegler AC, et al. Oxidative stress in neurodegenerative diseases: from molecular mechanisms to clinical applications. Oxid Med Cell Longev. 2017;2017:12.

27. Ricci C, Pastukh V, Leonard J, et al. Mitochondrial DNA damage triggers mitochondrial-superoxide generation and apoptosis. Am J Physiol Cell Physiol. 2008;294:C413-22.

28. Deshmukh P, Unni S, Krishnappa G, et al. The Keap1-Nrf2 pathway: promising therapeutic target to counteract ROS-mediated damage in cancers and neurodegenerative diseases. Biophys Rev. 2017;9:41-56.

29. Rangasamy T, Guo J, Mitzner WA, et al. Disruption of Nrf2 enhances susceptibility to severe airway inflammation and asthma in mice. J Exp Med. 2005;202:47-59.

30. Aoki Y, Sato H, Nishimura N, et al. Accelerated DNA adduct formation in the lung of the Nrf2 knockout mouse exposed to diesel exhaust, oxicol. Appl Pharmacol. 2001;173:154-60.

31. Zhang Z, Qu J, Zheng C, et al. Nrf2 antioxidant pathway suppresses Numb-mediated epithelial-mesenchymal transition during pulmonary fibrosis. Cell Death Dis. 2018;9:83.

32. Papaiahgari S, Yerrapureddy A, Reddy SR, et al. Genetic and pharmacologic evidence links oxidative stress to ventilator-induced lung injury in mice. Am J Respir Crit Care Med. 2007;176:1222-35.

33. Fratta AM, Stranieri C, Ferrari M, et al. Oxidative stress and Nrf2 expression in peripheral blood mononuclear cells derived from COPD patients: an observational longitudinal study. Respir Res. 2020;21:37.

34. Yamada K, Asai K, Nagayasu F, et al. Impaired nuclear factor erythroid 2-related factor 2 expression increases apoptosis of airway epithelial cells in patients with chronic obstructive pulmonary disease due to cigarette smoking. BMC Pulm Med. 2016;16:27.

35. Liao W, Lim AYH, Tan WSD, et al. Restoration of HDAC2 and Nrf2 by andrographolide overcomes corticosteroid resistance in chronic obstructive pulmonary disease. Br J Pharmacol. 2020. https://doi. org/10.1111/bph.15080.

36. Barnes PJ. Oxidative stress-based therapeutics in COPD. Redox Biol. 2020;33:101544.

37. Kirkham PA, Barnes PJ. Oxidative stress in COPD. Chest. 2013;144:266-73.

38. Tan WD, Shen H-M, Wong WF. Dysregulated autophagy in COPD: A pathogenic process to be deciphered. Pharmacol Res. 2019;144:1-7.

39. Ichinose M, Sugiura $H$, Yamagata $S$, et al. Increase in reactive nitrogen species production in chronic obstructive pulmonary disease airways. Am J Respir Crit Care Med. 2000;162:701-6.

40. Rahman I, van Schadewijk AA, Crowther AJ, et al. 4-Hydroxy-2-nonenal, a specific lipid peroxidation product, is elevated in lungs of patients with chronic obstructive pulmonary disease. Am J Respir Crit Care Med. 2002;166:490-5

41. Igishi T, Hitsuda Y, Kato K, et al. Elevated urinary 8-hydroxydeoxyguanosine, a biomarker of oxidative stress, and lack of association with antioxidant vitamins in chronic obstructive pulmonary disease. Respirology. 2003:8:455-60.

42. Dekhuijzen P, Aben K, Dekker I, et al. Increased exhalation of hydrogen peroxide in patients with stable and unstable chronic obstructive pulmonary disease. Am J Respir Crit Care Med. 1996;154:813-6.
43. Montuschi P, Collins JV, Ciabattoni G, et al. Exhaled 8-isoprostane as an in vivo biomarker of lung oxidative stress in patients with COPD and healthy smokers. Am J Respir Crit Care Med. 2000;162:1175-7.

44. Nowak D, Kasielski M, Antczak A, et al. Increased content of thiobarbituric acid-reactive substances and hydrogen peroxide in the expired breath condensate of patients with stable chronic obstructive pulmonary disease: no significant effect of cigarette smoking. Respir Med. 1999;93:389-96.

45. Kelly F, Mudway I. Protein oxidation at the air-lung interface. Amino Acids. 2003;25:375-96.

46. Maestrelli P, Paska C, Saetta M, et al. Decreased haem oxygenase-1 and increased inducible nitric oxide synthase in the lung of severe COPD patients. Eur Respir J. 2003;21:971-6.

47. Tomaki M, Sugiura $H$, Koarai A, et al. Decreased expression of antioxidant enzymes and increased expression of chemokines in COPD lung. Pulm Pharmacol Ther. 2007;20:596-605.

48. Tavilani H, Nadi E, Karimi J, et al. Oxidative stress in COPD patients, smokers, and non-smokers. Respir Care. 2012;57:2090-4.

49. Ahmad A, Shameem M, Husain Q. Altered oxidant-antioxidant levels in the disease prognosis of chronic obstructive pulmonary disease. Int J Tuberc Lung D. 2013;17:1104-9.

50. Hoffmann RF, Zarrintan S, Brandenburg SM, et al. Prolonged cigarette smoke exposure alters mitochondrial structure and function in airway epithelial cells. Respir Res. 2013;14:97.

51. Belchamber KB, Singh R, Wedzicha JA, et al. Elevated mitochondrial reactive oxygen species in COPD macrophages at exacerbation and with bacterial phagocytosis, B34 All things must pass: copd exacerbations. New York: American Thoracic Society; 2015. p. A6377-A6377.

52. Santos M, Oliveira A, Viegas-Crespo A, et al. Systemic markers of the redox balance in chronic obstructive pulmonary disease. Biomarkers. 2004;9:461-9.

53. Betsuyaku T, Fuke $S$, Inomata T, et al. Bronchiolar epithelial catalase is diminished in smokers with mild COPD. Eur Respir J. 2013;42:42-53.

54. Smolonska J, Wijmenga C, Postma DS, et al. Meta-analyses on suspected chronic obstructive pulmonary disease genes: a summary of 20 years' research. Am J Respir Crit Care Med. 2009;180:618-31.

55. Ito K, Ito M, Elliott WM, et al. Decreased histone deacetylase activity in chronic obstructive pulmonary disease. N Engl J Med. 2005;352:1967-76.

56. Szulakowski P, Crowther AJ, Jiménez LA, et al. The effect of smoking on the transcriptional regulation of lung inflammation in patients with chronic obstructive pulmonary disease. Am J Respir Crit Care Med. 2006;174:41-50.

57. Rahman I, Adcock I. Oxidative stress and redox regulation of lung inflammation in COPD. Eur Respir J. 2006;28:219-42.

58. Maziak W, Loukides S, Culpitt S, et al. Exhaled nitric oxide in chronic obstructive pulmonary disease. Am J Respir Crit Care Med. 1998;157:998-1002.

59. Hogg JC, Timens W. The pathology of chronic obstructive pulmonary disease. Annu Rev Pathol-mech. 2009;4:435-59.

60. Mercado N, Ito K, Barnes PJ. Accelerated ageing of the lung in COPD: new concepts. Thorax. 2015;70:482-9.

61. Tsuji T, Aoshiba K, Nagai A. Alveolar cell senescence in patients with pulmonary emphysema. Am J Respir Crit Care Med. 2006;174:886-93.

62. Marwick JA, Kirkham PA, Stevenson CS, et al. Cigarette smoke alters chromatin remodeling and induces proinflammatory genes in rat lungs. Am J Respir Cell Mol Biol. 2004;31:633-42.

63. Yang SR, Wright J, Bauter M, et al. Sirtuin regulates cigarette smokeinduced proinflammatory mediator release via RelA/p65 NF-kB in macrophages in vitro and in rat lungs in vivo: implications for chronic inflammation and aging. Am J Physiol Lung Cell Mol Physiol. 2007;292:L567-76.

64. Barnes PJ. How corticosteroids control inflammation: quintiles prize lecture 2005. Br J Pharmacol. 2006;148:245-54.

65. De Godoy I, Donahoe M, Calhoun WJ, et al. Elevated TNF-alpha production by peripheral blood monocytes of weight-losing COPD patients. Am J Respir Crit Care Med. 1996;153:633-7.

66. Huiart L, Ernst P, Suissa S. Cardiovascular morbidity and mortality in COPD. Chest. 2005;128:2640-6. 
67. Gao W, Li L, Wang Y, et al. Bronchial epithelial cells: the key effector cells in the pathogenesis of chronic obstructive pulmonary disease? Respirology. 2015;20:722-9.

68. Takabatake N, Nakamura H, Abe S, et al. The relationship between chronic hypoxemia and activation of the tumor necrosis factor-a system in patients with chronic obstructive pulmonary disease. Am J Respir Crit Care Med. 2000;161:1179-84.

69. Henricks PA, Nijkamp FP. Reactive oxygen species as mediators in asthma. Pulm Pharmacol Ther. 2001;14:409-21.

70. Parola M, Bellomo G, Robino G, et al. 4-Hydroxynonenal as a biological signal: molecular basis and pathophysiological implications. Antioxid Redox Signal. 1999;1:255-84.

71. Ji C, Amarnath V, Pietenpol JA, et al. 4-hydroxynonenal induces apoptosis via caspase-3 activation and cytochrome c release. Chem Res Toxicol. 2001;14:1090-6.

72. Takeyama K, Agustí C, Ueki I, et al. Neutrophil-dependent goblet cell degranulation: role of membrane-bound elastase and adhesion molecules. Am J Physiol Lung Cell Mol Physiol. 1998;275:L294-302.

73. Burgel P, Nadel J. Roles of epidermal growth factor receptor activation in epithelial cell repair and mucin production in airway epithelium. Thorax. 2004;59:992-6.

74. Yan K, Salome C, Woolcock A. Prevalence and nature of bronchial hyperresponsiveness in subjects with chronic obstructive pulmonary disease. Am Rev Respir Dis. 1985;132:25-9.

75. Schafroth ST, Leuppi JD. Bronchial hyper-responsiveness and exhaled nitric oxide in chronic obstructive pulmonary disease. Swiss Med Wkly. 2007;137:385-91.

76. Bai TR, Zhou D, Weir T, et al. Substance P (NK1)-and neurokinin A (NK2)receptor gene expression in inflammatory airway diseases. Am J Physiol Lung Cell Mol Physiol. 1995;269:L309-17.

77. Kinsella BT, O'Mahony DJ, Fitzgerald GA. The human thromboxane A2 receptor a isoform (TPa) functionally couples to the $\mathrm{G}$ proteins $\mathrm{Gq}$ and G11 in vivo and is activated by the isoprostane 8-epi prostaglandin F2a. J Pharmacol Exp Ther. 1997;281:957-64.

78. Caramori G, Adcock IM, Casolari P, et al. Unbalanced oxidant-induced DNA damage and repair in COPD: a link towards lung cancer. Thorax. 2011;66:521-7.

79. Kirkham PA, Caramori G, Casolari P, et al. Oxidative stress-induced antibodies to carbonyl-modified protein correlate with severity of chronic obstructive pulmonary disease. Am J Respir Crit Care Med. 2011;184:796-802.

80. To PG. Global initiative for chronic obstructive lung. Am J Respir Crit Care Med. 2018;197:1.

81. Santus P, Buccellati C, Centanni S, et al. Bronchodilators modulate inflammation in chronic obstructive pulmonary disease subjects. Pharmacol Res. 2012;66:343-8.

82. Smith $L$, Houston M. Increased levels of glutathione in bronchoalveolar lavage fluid from patients with asthma. Am Rev Respir Dis. 1993;147:1461-1461.

83. Van Der Vliet A, O'Neill CA, Cross CE, et al. Determination of low-molecular-mass antioxidant concentrations in human respiratory tract lining fluids. Am J Physiol Lung Cell Mol Physiol. 1999;276:L289-96.

84. Kelly F, Cotgrove M, Mudway I. Respiratory tract lining fluid antioxidants: the first line of defence against gaseous pollutants. Cent Eur J Public Health. 1996:4:11-4

85. Rustow B, Haupt R, Stevens P, et al. Type II pneumocytes secrete vitamin E together with surfactant lipids. Am J Physiol Lung Cell Mol Physiol. 1993;265:L133-9.

86. Sevanian A, Elsayed N, Hacker A. Effects of vitamin E deficiency and nitrogen dioxide exposure on lung lipid peroxidation: use of lipid epoxides and malonaldehyde as measures of peroxidation. J Toxicol Environ Health. 1982;10:743-56.

87. Cantin AM, Fells GA, Hubbard RC, et al. Antioxidant macromolecules in the epithelial lining fluid of the normal human lower respiratory tract. J Clin Invest. 1990;86:962-71.

88. Pietarinen-Runtti P, Raivio KO, Saksela M, et al. Antioxidant enzyme regulation and resistance to oxidants of human bronchial epithelial cells cultured under hyperoxic conditions. Am J Respir Cell Mol Biol. 1998;19:286-92.

89. Sahin U, Unlü M, Ozgüner F, et al. Lipid peroxidation and glutathione peroxidase activity in chronic obstructive pulmonary disease exacerbation: prognostic value of malondialdehyde. J Basic Clin Physiol Pharmacol. 2001;12:59-68.

90. Willis L, Hayes D, Mansour HM. Therapeutic liposomal dry powder inhalation aerosols for targeted lung delivery. Lung. 2012;190:251-62.

91. Pinheiro M, Lúcio M, Lima JL, et al. Liposomes as drug delivery systems for the treatment of TB. Nanomed. 2011;6:1413-28.

92. Allen TM. Liposomal drug formulations. Drugs. 1998;56:747-56

93. Turrens JF, Crapo JD, Freeman B. Protection against oxygen toxicity by intravenous injection of liposome-entrapped catalase and superoxide dismutase. J Clin Invest. 1984;73:87-95.

94. Suntres ZE, Shek PN. Prevention of phorbol myristate acetateinduced acute lung injury by a-tocopherol liposomes. J Drug Target. 1995:3:201-8.

95. Barnard ML, Baker RR. Mitigation of oxidant injury to lung microvasculature by intratracheal instillation of antioxidant enzymes. Am J Physiol Lung Cell Mol Physiol. 1993;265:L340-5.

96. Walther FJ, David-Cu R, Lopez SL. Antioxidant-surfactant liposomes mitigate hyperoxic lung injury in premature rabbits. Am J Physiol Lung Cell Mol Physiol. 1995;269:L613-7.

97. Thibeault DW, Rezaiekhaligh M, Mabry S, et al. Prevention of chronic pulmonary oxygen toxicity in young rats with liposome-encapsulated catalase administered intratracheally. Pediatr Pulmonol. 1991;11:318-27.

98. Cooke RW, Drury JA. Reduction of oxidative stress marker in lung fluid of preterm infants after administration of intra-tracheal liposomal glutathione. Neonatology. 2005;87:178-80.

99. Hoesel LM, Flierl MA, Niederbichler AD, et al. Ability of antioxidant liposomes to prevent acute and progressive pulmonary injury. Antioxid Redox Signal. 2008;10:963-72.

100. Ourique AF, dos SantosChaves P, Souto GD, et al. Redispersible liposomal-N-acetylcysteine powder for pulmonary administration: Development, in vitro characterization and antioxidant activity. Eur J Pharm Sci. 2014;65:174-82.

101. Wigenstam E, Rocksén D, Ekstrand-Hammarström B, et al. Treatment with dexamethasone or liposome-encapsuled vitamin E provides beneficial effects after chemical-induced lung injury. Inhal Toxicol. 2009;21:958-64.

102. Manconi M, Manca ML, Valenti D, et al. Chitosan and hyaluronan coated liposomes for pulmonary administration of curcumin. Int J Pharm. 2017:525:203-10.

103. Dekhuijzen PR, Batsiou M, Bjermer L, et al. Incidence of oral thrush in patients with COPD prescribed inhaled corticosteroids: effect of drug, dose, and device. Respir Med. 2016;120:54-63.

104. Barjaktarevic IZ, Arredondo AF, Cooper CB. Positioning new pharmacotherapies for COPD. Int J Chron Obstruct Pulmon Dis. 2015;10:1427-42.

105. Paranjpe M, Müller-Goymann CC. Nanoparticle-mediated pulmonary drug delivery: a review. Int J Mol Sci. 2014;15:5852-73.

106. Hood ED, Chorny M, Greineder CF, et al. Endothelial targeting of nanocarriers loaded with antioxidant enzymes for protection against vascular oxidative stress and inflammation. Biomaterials. 2014;35:3708-15.

107. Omlor AJ, Nguyen J, Bals R, et al. Nanotechnology in respiratory medicine. Respir Res. 2015;16:64

108. Villegas L, Stidham T, Nozik-Grayck E. Oxidative Stress and Therapeutic Development in Lung Diseases. J Pulm Respir Med. 2014:4:99.

109. Castellani S, Trapani A, Spagnoletta A, et al. Nanoparticle delivery of grape seed-derived proanthocyanidins to airway epithelial cells dampens oxidative stress and inflammation. J Transl Med. 2018;16:140.

110. Carvalho FO, Silva ÉR, Nunes PS, et al. Effects of the solid lipid nanoparticle of carvacrol on rodents with lung injury from smoke inhalation. Naunyn-Schmiedeberg's Arch Pharmacol. 2019;393:1-11.

111. Geiser M, Quaile O, Wenk A, et al. Cellular uptake and localization of inhaled gold nanoparticles in lungs of mice with chronic obstructive pulmonary disease. Part Fibre Toxicol. 2013;10:19.

112. Gil D, Rodriguez J, Ward B, et al. Antioxidant activity of SOD and catalase conjugated with nanocrystalline ceria. Bioengineering. 2017:4:18.

113. Li X, Yang H, Wu S, et al. Suppression of PTPN6 exacerbates aluminum oxide nanoparticle-induced COPD-like lesions in mice through activation of STAT pathway. Part Fibre Toxicol. 2017;14:53. 
114. Jeong D, Kang C, Jung E, et al. Porous antioxidant polymer microparticles as therapeutic systems for the airway inflammatory diseases. J Control Release. 2016;233:72-80.

115. Kim S, Park H, Song Y, et al. Reduction of oxidative stress by p-hydroxybenzyl alcohol-containing biodegradable polyoxalate nanoparticulate antioxidant. Biomaterials. 2011;32:3021-9.

116. Yoo D, Guk K, Kim H, et al. Antioxidant polymeric nanoparticles as novel therapeutics for airway inflammatory diseases. Int J Pharm. 2013:450:87-94

117. Wattamwar PP, Mo Y, Wan R, et al. Antioxidant activity of degradable polymer poly (trolox ester) to suppress oxidative stress injury in the cells. Adv Funct Mater. 2010;20:147-54

118. Craparo EF, Ferraro M, Pace E, et al. Polyaspartamide-based nanoparticles loaded with fluticasone propionate and the in vitro evaluation towards cigarette smoke effects. Nanomaterials. 2017;7:222

119. Jacobs C, Müller RH. Production and characterization of a budesonide nanosuspension for pulmonary administration. Pharm Res. 2002;19:189-94.

120. Lee WH, Loo CY, Young PM, et al. Curcumin nanoparticles attenuates inflammation caused by macrophages: effects of nanoparticles' surface charges. J Aerosol Med Pulm Drug Deliv. 2014;21:A7-A7.

121. Lee $\mathbf{W}-\mathrm{H}$, Loo C-Y, Young PM, et al. Curcumin nanoparticles attenuate production of pro-inflammatory markers in lipopolysaccharide-induced macrophages. Pharm Res. 2016:33:315-27.

122. Mohamed A, Pekoz AY, Ross K, et al. Pulmonary delivery of Nanocomposite Microparticles (NCMPs) incorporating miR-146a for treatment of COPD. Int J Pharm. 2019;569:118524-31.

123. Chikuma K, Arima K, Asaba Y, et al. The potential of lipid-polymer nanoparticles as epigenetic and ROS control approaches for COPD. Free Radic Res. 2019;1:1-12.

124. Dördelmann G, Kozlova D, Karczewski S, et al. Calcium phosphate increases the encapsulation efficiency of hydrophilic drugs (proteins, nucleic acids) into poly (d, I-lactide-co-glycolide acid) nanoparticles for intracellular delivery. J Mater Chem B. 2014;2:7250-9.

125. Frede A, Neuhaus B, Knuschke T, et al. Local delivery of siRNA-loaded calcium phosphate nanoparticles abates pulmonary inflammation. Nanomed Nanotechnol Biol Med. 2017;13:2395-403.

126. Kaminskas LM, Boyd BJ, Karellas $P$, et al. The impact of molecular weight and PEG chain length on the systemic pharmacokinetics of PEGylated poly I-lysine dendrimers. Mol Pharm. 2008;5:449-63.

127. Ryan GM, Kaminskas LM, Kelly BD, et al. Pulmonary administration of PEGylated polylysine dendrimers: absorption from the lung versus retention within the lung is highly size-dependent. Mol Pharm. 2013;10:2986-95.

128. Zhong Q, Merkel OM, Reineke JJ, et al. Effect of the route of administration and PEGylation of poly (amidoamine) dendrimers on their systemic and lung cellular Biodistribution. Mol Pharm. 2016;13:1866-78.

129. Conti DS, Brewer D, Grashik J, et al. Poly (amidoamine) dendrimer nanocarriers and their aerosol formulations for siRNA delivery to the lung epithelium. Mol Pharm. 2014;11:1808-22

130. Bohr A, Tsapis N, Foged C, et al. Treatment of acute lung inflammation by pulmonary delivery of anti-TNF-a siRNA with PAMAM dendrimers in a murine model. Eur J Pharm Biopharm. 2020;156:114-20.

131. Thanki K, Zeng $X$, Justesen $S$, et al. Engineering of small interfering RNA loaded lipidoid-poly (DL-lactic-co-glycolic acid) hybrid nanoparticles for highly efficient and safe gene silencing: A quality by design-based approach. Eur J Pharm Biopharm. 2017;120:22-33.

132. Raula J, Rahikkala A, Halkola T, et al. Coated particle assemblies for the concomitant pulmonary administration of budesonide and salbutamol sulphate. Int J Pharm. 2013:441:248-54.

133. Passi M, Kumar V, Packirisamy G. Theranostic nanozyme: Silk fibroin based multifunctional nanocomposites to combat oxidative stress. Mater Sci Eng C. 2020;107:110255.

134. Müller R, Radtke M, Wissing S. Nanostructured lipid matrices for improved microencapsulation of drugs. Int J Pharm. 2002;242:121-8.

135. Mehnert W. Solid lipid nanoparticles: production, characterization and applications. Adv Drug Del Rev. 2012;64:83-101.

136. Ding Y, Jiang Z, Saha K, et al. Gold nanoparticles for nucleic acid delivery. Mol Ther. 2014;22:1075-83.
137. Fukui $\mathrm{H}$, Iwahashi $\mathrm{H}$, Endoh $\mathrm{S}$, et al. Ascorbic acid attenuates acute pulmonary oxidative stress and inflammation caused by zinc oxide nanoparticles. J Occup Health. 2015:57:118-25.

138. Suliman YAO, Ali D, Alarifi S, et al. Evaluation of cytotoxic, oxidative stress, proinflammatory and genotoxic effect of silver nanoparticles in human lung epithelial cells. Environ Toxicol. 2015;30:149-60.

139. Ni S, Liu Y, Tang Y, et al. GABAB receptor ligand-directed trimethyl chitosan/tripolyphosphate nanoparticles and their pMDI formulation for survivin siRNA pulmonary delivery. Carbohydr Polym. 2018:179:135-44.

140. Rytting E, Nguyen J, Wang $X$, et al. Biodegradable polymeric nanocarriers for pulmonary drug delivery. Expert Opin Drug Del. 2008;5:629-39.

141. Vij N, Min T, Marasigan R, et al. Development of PEGylated PLGA nanoparticle for controlled and sustained drug delivery in cystic fibrosis. J Nanobiotechnol. 2010:8:22.

142. Zhou L, Zhao J, Chen Y, et al. MoS2-ALG-Fe/GOx hydrogel with Fenton catalytic activity for combined cancer photothermal, starvation, and chemodynamic therapy. Colloids Surf B Biointerfaces. 2020;195:111243.

143. Madl AK, Plummer LE, Carosino C, et al. Nanoparticles, lung injury, and the role of oxidant stress. Annu Rev Physiol. 2014;76:447-65.

144. Khanna P, Ong C, Bay BH, et al. Nanotoxicity: an interplay of oxidative stress, inflammation and cell death. Nanomaterials. 2015;5:1163-80.

145. Dailey LA, Kissel T. New poly(lactic-co-glycolic acid) derivatives: Modular polymers with tailored properties. Drug Discov Today Tech. 2005;2:7-13.

146. Mehta P, Kadam S, Pawar A, et al. Dendrimers for pulmonary delivery: current perspectives and future challenges. New J Chem. 2019;43:8396-409.

147. Akinc A, Zumbuehl A, Goldberg M, et al. A combinatorial library of lipid-like materials for delivery of RNAi therapeutics. Nat Biotechnol. 2008:26:561-9.

148. Wang S, Yang $X$, Zhou L, et al. 2D nanostructures beyond graphene: preparation, biocompatibility and biodegradation behaviors. J Mater Chem B. 2020;8:2974-89.

149. Boland S, Guadagnini R, Baeza-Squiban A, et al. Nanoparticles used in medical applications for the lung: hopes for nanomedicine and fears for nanotoxicity. J Phys Conf Ser. 2011;304:012031.

150. Liu W, Hu T, Zhou L, et al. Nrf2 protects against oxidative stress induced by $\mathrm{SiO} 2$ nanoparticles. Nanomed. 2017;12:2303-18.

151. Heyder J, Gebhart J, Rudolf G, et al. Deposition of particles in the human respiratory tract in the size range $0.005-15 \mu \mathrm{m}$. J Aerosol Sci. 1986:17:811-25.

152. Sung JC, Pulliam BL, Edwards DA. Nanoparticles for drug delivery to the lungs. Trends Biotechnol. 2007;25:563-70.

153. Pulivendala G, Bale S, Godugu C. Inhalation of sustained release microparticles for the targeted treatment of respiratory diseases. Drug Deliv Transl Re. 2019;3:1-15.

154. Labiris N, Dolovich M. Pulmonary drug delivery. Part I: physiological factors affecting therapeutic effectiveness of aerosolized medications. $\mathrm{Br}$ J Clin Pharmacol. 2003;56:588-99.

155. Lin Y-W, Wong J, Qu L, et al. Powder production and particle engineering for dry powder inhaler formulations. Curr Pharm Des. 2015:21:3902-16.

156. Jones LH, Burrows J, Feeder N, et al. Molecular hybridization yields triazole bronchodilators for the treatment of COPD. Bioorg Med Chem Lett. 2015;25:5121-6.

157. Moura CU, Neves F, Costa E. Impact of jet-milling and wet-polishing size reduction technologies on inhalation API particle properties. Powder Technol. 2016;298:90-8.

158. Zellnitz S, Zellnitz L, Müller MT, et al. Impact of drug particle shape on permeability and cellular uptake in the lung. Eur J Pharm Sci. 2019:139:105065.

159. Muralidharan P, Hayes D, Black SM, et al. Microparticulate/nanoparticulate powders of a novel Nrf2 activator and an aerosol performance enhancer for pulmonary delivery targeting the lung Nrf2/Keap-1 pathway. Mol Syst Des Eng. 2016;1:48-65.

160. Sansone F, Aquino R, Del Gaudio P, et al. Physical characteristics and aerosol performance of naringin dry powders for pulmonary delivery prepared by spray-drying. Eur J Pharm Biopharm. 2009;72:206-13.

161. Menon B, Kaur C, Vardhan H, et al. Evaluation of indacaterol and glycopyrronium as inhalation powder on systemic inflammatory and oxidative stress parameters in severe COPD. Eur Respir J. 2016;12:11. 
162. Trotta V, Lee W-H, Loo C-Y, et al. Co-spray dried resveratrol and budesonide inhalation formulation for reducing inflammation and oxidative stress in rat alveolar macrophages. Eur J Pharm Sci. 2016;86:20-8.

163. Trotta V, Haghi M, Scalia S, et al. Resveratrol, a Novel Spray Dried Inhalation Powder for the Treatment of COPD and other Inflammatory Lung Diseases. J Aerosol Med Pulm Drug Deliv. 2015;11:198.

164. Trotta $\mathrm{V}$, Lee $\mathrm{W}-\mathrm{H}$, Loo C-Y, et al. In vitro biological activity of resveratrol using a novel inhalable resveratrol spray-dried formulation. Int J Pharm. 2015;491:190-7.

165. Liu T, Han M, Tian F, et al. Budesonide nanocrystal-loaded hyaluronic acid microparticles for inhalation: In vitro and in vivo evaluation. Carbohydr Polym. 2018;181:1143-52

166. Fallacara A, Busato L, Pozzoli M, et al. Combination of urea-crosslinked hyaluronic acid and sodium ascorbyl phosphate for the treatment of inflammatory lung diseases: an in vitro study. Eur J Pharm Sci. 2018;120:96-106

167. Fallacara A, Busato L, Pozzoli M, et al. Co-spray-dried urea cross-linked hyaluronic acid and sodium ascorbyl phosphate as novel inhalable dry powder formulation. J Pharm Sci. 2019;108:2964-71.

168. Yoo N-Y, Baik H-J, Lee B-R, et al. Sustained release of anthocyanin from porous poly (lactic-co-glycolide) microsparticles developed for the treatment of chronic obstructive pulmonary disease. J Pharm Investig. 2010;40:231-6.

169. Yoo NY, Youn YS, Oh NM, et al. Antioxidant encapsulated porous poly (lactide-co-glycolide) microparticles for developing long acting inhalation system. Colloids Surf B Biointerfaces. 2011;88:419-24.

170. Zhang L, Zhang X, Li J, et al. Optimization of budesonide-loaded largeporous microparticles for inhalation using quality by design approach. J Drug Deliv Sci Technol. 2019;53:101140.

171. Amore E, Ferraro M, Manca ML, et al. Mucoadhesive solid lipid microparticles for controlled release of a corticosteroid in the chronic obstructive pulmonary disease treatment. Nanomed. 2017:12:2287-302.

172. Amore E, Manca ML, Ferraro M, et al. Salmeterol Xinafoate (SX) loaded into mucoadhesive solid lipid microparticles for COPD treatment. Int J Pharm. 2019;562:351-8.

173. Dormenval C, Lokras A, Cano-Garcia G, et al. Identification of factors of importance for spray drying of small interfering RNA-loaded lipidoidpolymer hybrid nanoparticles for inhalation. Pharm Res. 2019;89:12.

174. Agnoletti M, Bohr A, Thanki K, et al. Inhalable siRNA-loaded nanoembedded microparticles engineered using microfluidics and spray drying. Eur J Pharm Biopharm. 2017;120:9-21.

175. El-Sherbiny IM, Smyth HD. Controlled release pulmonary administration of curcumin using swellable biocompatible microparticles. Mol Pharm. 2012;9:269-80.
176. Šimková K, Joost B, Imanidis G. Production of fast-dissolving lowdensity powders for improved lung deposition by spray drying of a nanosuspension. Eur J Pharm Biopharm. 2020;146:19-31.

177. Pápay ZE, Kósa A, Böddi B, et al. Study on the pulmonary delivery system of apigenin-loaded albumin nanocarriers with antioxidant activity. J Aerosol Med Pulm Drug Deliv. 2017;30:274-88.

178. Dumont $\mathrm{E}$, Oliver A, loannou C, et al. A novel inhaled dry-powder formulation of ribavirin allows for efficient lung delivery in healthy participants and those with COPD in a Phase 1 study. Antimicrob Agents Chemother. 2020;12:2.

179. Liang Z, Ni R, Zhou J, et al. Recent advances in controlled pulmonary drug delivery. Drug Discov Today. 2015;20:380-9.

180. Mour C, Neves F, Costa E. Impact of jet-milling and wet-polishing size reduction technologies on inhalation API particle properties. Powder Technol. 2016;298:90-8.

181. Jensen DMK, Cun D, Maltesen MJ, et al. Spray drying of siRNA-containing PLGA nanoparticles intended for inhalation. J Control Release. 2010;142:138-45.

182. Tsapis N, Bennett D, Jackson B, et al. Trojan particles: large porous carriers of nanoparticles for drug delivery. Proc Natl Acad Sci. 2002;99:12001-5

183. Mansuri S, Kesharwani P, Jain K, et al. Mucoadhesion: a promising approach in drug delivery system. React Funct Polym. 2016;100:151-72.

184. Külkamp IC, Rabelo BD, Berlitz SJ, et al. Nanoencapsulation improves the In Vitro antioxidant activity of lipoic acid. J Biomed Nanotechnol. 2011;7:598-607.

185. Hadinoto K, Zhu K, Tan RB. Drug release study of large hollow nanoparticulate aggregates carrier particles for pulmonary delivery. Int J Pharm. 2007;341:195-206.

186. Grenha A, Remuñán-López C, Carvalho EL, et al. Microspheres containing lipid/chitosan nanoparticles complexes for pulmonary delivery of therapeutic proteins. Eur J Pharm Biopharm. 2008;69:83-93.

187. Ruge CA, Kirch J, Lehr C-M. Pulmonary drug delivery: from generating aerosols to overcoming biological barriers-therapeutic possibilities possibilities and technological challenges. Lancet Respir Med. 2013:1:402-13.

\section{Publisher's Note}

Springer Nature remains neutral with regard to jurisdictional claims in published maps and institutional affiliations.
Ready to submit your research? Choose BMC and benefit from:

- fast, convenient online submission

- thorough peer review by experienced researchers in your field

- rapid publication on acceptance

- support for research data, including large and complex data types

- gold Open Access which fosters wider collaboration and increased citations

- maximum visibility for your research: over $100 \mathrm{M}$ website views per year

At $\mathrm{BMC}$, research is always in progress.

Learn more biomedcentral.com/submissions 